\title{
Bulk Texture Evolution of Nanolamellar Zr-Nb Composites Processed Via Accumulative Roll Bonding
}

\author{
J.S. Carpenter ${ }^{1}$, T. Nizolek ${ }^{2,3}$, R.J. McCabe ${ }^{1}$, M. Knezevic ${ }^{4}$, S.J. Zheng ${ }^{3,5}$, B.P. Eftink ${ }^{3,6}$, J.E. Scott ${ }^{1}$, S.C. \\ Vogel $^{7}$, T.M. Pollock ${ }^{2}$, N.A. Mara ${ }^{1,3}$, I.J. Beyerlein ${ }^{8}$ \\ ${ }^{1}$ Materials Science and Technology Division, Los Alamos National Laboratory, Los Alamos, NM, 87545, USA \\ ${ }^{2}$ Materials Department, University of California Santa Barbara, Santa Barbara, CA, 93106-5050, USA \\ ${ }^{3}$ Materials Physics and Applications Division, Los Alamos National Laboratory, Los Alamos, NM, 87545, USA \\ ${ }^{4}$ Department of Mechanical Engineering, University of New Hampshire, Durham, NH, 03824, USA \\ ${ }^{5}$ Institute of Metal Research, Chinese Academy of Sciences Shenyang, China 110016 \\ ${ }^{6}$ Department of Materials Science and Engineering, University of Illinois at Urbana-Champaign, Urbana, IL, 61801, \\ USA \\ ${ }^{7}$ Los Alamos Neutron Science Center, Los Alamos National Laboratory, Los Alamos, NM 87545, USA \\ ${ }^{8}$ Theoretical Division, Los Alamos National Laboratory, Los Alamos, NM, 87545, USA
}

\begin{abstract}
It was recently demonstrated that bulk two-phase 50/50 $\mathrm{Zr}$-Nb nanolayered composites with $90 \mathrm{~nm}$ individual layers can be fabricated from an initial coarse-layered composite with $1 \mathrm{~mm}$ layers via the severe plastic deformation process of accumulative roll bonding. During the deformation, the $\mathrm{Zr}$ phase retained its hcp crystal structure and the $\mathrm{Zr}$-Nb interface remained sharp. Here we use a combination of neutron diffraction and dislocation-based polycrystal plasticity constitutive modeling to assess the evolution of texture and deformation mechanisms over a four order-of-magnitude range in layer thicknesses. The phase textures in the nanocomposite strongly deviate from that of $\mathrm{Zr}$ or $\mathrm{Nb}$ rolled in monolithic form, becoming highly peaked and intense. The model suggests that texture development in the $\mathrm{Nb}$ phase is associated with multiple slip and contributions from both $\{112\}<110>$ slip and $\{110\}<110>$ slip. In the Zr phase the model suggests that the texture develops due to a predominance of prismatic $<$ a $>$ and basal $<$ a $>$ slip.
\end{abstract}

$\underline{\text { Keywords: }}$ texture, severe plastic deformation, accumulative roll bonding, neutron diffraction, composites, nanostructures 


\section{Introduction:}

When the layer thickness $(h)$ is reduced to the nanoscale, multilayered bimetallic composites have been shown to exhibit improved strength [1-3], thermal stability [4, 5], resistance to shock damage [6], and resistance to radiation damage $[7,8]$ compared to the constituent materials in bulk form. The majority of research in this area has been conducted on bimetallic systems fabricated using a bottom-up approach such as magnetron sputtering or other deposition methods [1-8]. The low deposition rate of these synthesis techniques makes them unsuitable for producing large volumes of material, precluding structural application of these otherwise exceptional materials.

Accumulative roll bonding (ARB) is a severe plastic deformation (SPD) technique, developed by Saito et al. [9], that has been used in recent years as a route for creating bulk multilayered composites of two dissimilar metals. As the ARB process uses standard metalworking equipment such as rolling mills, this technique is seen as both an economically viable and industrially scalable processing route for creating ultra-fine grained and nanograined metallic composites [10]. This technique has been applied successfully to create bimetallic composites with a variety of crystal structure combinations such as $\mathrm{fcc} / \mathrm{fcc}$ [11-13], fcc/bcc [14], fcc/hcp [10, 15-20] and bcc/hcp [21]. Large, single-pass reductions are often necessary to achieve bonding during ARB between vicinal neighboring layers. These large reductions coupled with different shear strengths and work hardening rates can promote intense shear banding and break-up of the layered structure prior to reaching the nanoscale regime [16]. The nanoscale regime, where $h<100 \mathrm{~nm}$, is where unique property combinations were achieved during bottom-up fabrication methodologies such as physical vapor deposition. In the past, ARB has had success in reducing $\mathrm{h}<100 \mathrm{~nm}$ with combinations of cubic crystal structures like with $\mathrm{Cu}-\mathrm{Nb}$ [14] and Ag-Fe [11].

Due to the reduced number of slip systems available, hcp materials have not been as amenable to nanostructuring through SPD methods as cubic materials. Without considering composites, many 
efforts have been made to make nano-grained $\mathrm{Zr}, \mathrm{Ti}, \mathrm{Be}, \mathrm{Mg}$, and $\mathrm{Zn}$ via SPD techniques, such as ball milling, equal channel angular extrusion (ECAE), ARB, and high pressure torsion (HPT) [15, 22-31]. Some success was achieved in creating small quantities of nanoscale hcp material using ball milling and HPT. The coarse-grained structure of commercial purity (CP) Ti was successfully refined to $80 \mathrm{~nm}$ by HPT in $[32,33]$ and by ARB at room temperature [34] as well as under warm conditions [35]. On the other hand, SPD techniques have only achieved $0.5 \mu \mathrm{m}$ grain size in Mg alloys [22, 36-38]. Prior attempts to refine the grain structure in Zr via SPD either led to submicron grains with grain diameters > $100 \mathrm{~nm}$ [23, $24,39,40]$ or a fraction of nanograins of Zr with an alternate crystal structure (omega-Zr, beta-Zr or fcc Zr) $[23-25,41]$. With single-phase commercial purity $Z r$, the final grain size reached with the ARB technique was $400 \mathrm{~nm}$ [42]. Bimetallic composites with hcp constituents such as Mg-Al [18], Ti-Al [20], Cu-Zn [16], Cu-Zr [17], Zr-Nb [40], and Al-Zn [15] have been synthesized using ARB. A controlled, continuous layered structure with $h<100$ nm layers, however, has not been achieved.

Nanolamellar Zr-Nb composites has recently been synthesized using the ARB process [21]. The key to achieving nanoscale layers appeared to be intermediate annealing treatments of $575^{\circ} \mathrm{C}$ for one hour between roll bonding passes. These annealing steps effectively suppressed shear banding and allowed for continued roll bonding to $\sim 90 \mathrm{~nm}$ individual layer thicknesses. This novel material can potentially lead to a number of interesting findings. In this work, we focus on texture evolution and deformation mechanisms during processing to the nanoscale.

Much is known about the large-strain deformation behavior of the individual constituents, $\mathrm{Nb}$ and $\mathrm{Zr}$, in monolithic, polycrystalline, and coarse-grained form ( $>1 \mathrm{um}$ and larger). For instance, their rolling textures after straining with or without subsequent annealing have been reported [43-45] and will be discussed in the results section of this paper. When combined with polycrystalline modeling for texture and stress-strain behavior, the plastic deformation mechanisms activated in rolling and other modes of deformation have been deduced. Based on these studies, these metals are generally expected 
to deform via multiple slip modes and not predominantly by twinning at the room temperature and quasi-static strain rates of the ARB process. Specifically, the Nb composition studied here has been found to deform primarily by $\{110\}<111>$ slip and secondly by $\{112\}<111>$ slip with no deformation twinning during large-strain rolling or uniaxial deformation $[40,46]$ over a wide range of temperatures and strain rates [47]. The high-purity $\mathrm{Zr}$ composition used here has been shown in [48] to deform primarily by prismatic slip, secondly by pyramidal $<c+a>$ slip, and after large strains also by basal slip. The latter phenomenon is interesting because generally, after small to moderate strains in single crystal and polycrystalline $Z r$, basal slip is expected to be negligible. However, in Yapici et al [39] who studied the large-strain behavior of high-purity Zr using ECAE, texture analysis and modeling suggested that basal slip in addition to prismatic and pyramidal slip was induced during the ECAE pass ( $100 \%$ simple shear per pass). Likewise, a study of deformation mechanisms in the $\mathrm{Zr}$ phase within a non-nanoscale $\mathrm{Zr}-\mathrm{Nb}$ composite fabricated via ARB (a total accumulated strain of 4 ) indicated that combinations of prismatic, pyramidal and non-negligible amounts of basal slip were responsible for its texture development [48]. The texture of the polycrystalline $\mathrm{Zr}$ phase in the $\mathrm{Zr}$-Nb composite was very similar to that of monolithic $\mathrm{Zr}$, suggesting that the substantial basal slip was an outcome of the SPD and not the coupling with $\mathrm{Nb}$ [40]. Since prior electron backscatter diffraction (EBSD) and neutron diffraction (NeD) revealed only a modest amount of twinning in this $\mathrm{Zr}$ composition at room temperature [49, 50], deformation twinning was not considered in this calculation.

Although much is known about the texture and deformation mechanisms in $\mathrm{Zr}$ and $\mathrm{Nb}$, the extreme strains characteristic of SPD techniques can substantially alter the texture and microstructure of single-phase and two-phase composites [51, 52]. Moreover, it has been shown that combinations of extreme strains and nanoscale grain dimensions can result in significant changes in deformation mechanisms from those expected of the constituents when deformed alone [53-57]. 
In this work, we take advantage of the unique opportunity to study the plastic behavior of ultrafine and nanograined $\mathrm{Zr}$ and $\mathrm{Nb}$ deformed to extreme levels of strain..

We will focus on these three specific areas:

1) The texture evolution of $\mathrm{Nb}$ during $\mathrm{ARB}$ processing of a $\mathrm{Nb} / \mathrm{fcc}$ composite has been wellcharacterized for several processing conditions $[14,53]$. The $\mathrm{Zr}-\mathrm{Nb}$ material synthesized for the present work allows for a comparative study of the texture evolution of $\mathrm{Nb}$ during processing of Nb-hcp and Nb-fcc composites with similar processing history, length scales, and microstructures.

2) The texture evolution of hcp $\mathrm{Zr}$ as grain size is reduced in the presence of a bcc metal will also be examined.

3) Texture is an indicator of the deformation mechanisms that accommodate plastic strain during roll bonding. The texture evolutions studied in 1 and 2 will be combined with polycrystalline modeling to ascertain the deformation mechanisms that are active at the nanoscale in these materials.

\section{Experimental Methods:}

Initial materials for the accumulative roll bonding (ARB) process consisted of $2 \mathrm{~mm}$ thick sheets of high-purity $\mathrm{Zr}$ and reactor-grade, high-purity $\mathrm{Nb}$ (99.97\% pure, ATI-Wah Chang). The nominal composition of the $\mathrm{Zr}$ expressed in weight parts per million (Wt. ppm) is $\mathrm{Hf} 35, \mathrm{Fe}<50, \mathrm{Al}<20, \mathrm{~V}<50, \mathrm{O}$ $<50, \mathrm{~N}<20, \mathrm{C}<22, \mathrm{Zr}$ balance. The composition for the $\mathrm{Nb}$ in (Wt. $\mathrm{ppm}$ ) is $\mathrm{C}<20, \mathrm{Fe}<25, \mathrm{H}<3, \mathrm{Hf}<30$, $\mathrm{Mo}<30, \mathrm{~N}<20, \mathrm{Ni}<20, \mathrm{O}<40, \mathrm{P}<30, \mathrm{Si}<25, \mathrm{Ta}=110, \mathrm{Ti}<30, \mathrm{~W}<30, \mathrm{Zr}<30$ and $\mathrm{Nb}$ balance.

$\mathrm{Zr}$ plate processing [58] consisted of upset forging, clock rolling, and annealing in order to provide a plate with a strong fiber texture aligned with the c-axis in the normal direction. Clock rolling is similar to traditional rolling except that the rolling direction is rotated around the plate normal for every 
subsequent pass such that the rolling direction is continuously changing. After this initial processing, the plate underwent further rolling and heat treatments [58]. The Zr plate utilized during the ARB process had equiaxed, twin-free grains of approximately $40 \mu \mathrm{m}$ in diameter and strong basal texture. The $\mathrm{Nb}$ plate was annealed such that it exhibited a recrystallized microstructure with a (111) fiber texture parallel with the normal direction (ND) of the plate. Nominal grain size in $\mathrm{Nb}$ after heat treatment was larger than that of $\mathrm{Zr}$ with an approximate grain diameter of $300 \mathrm{um}$. Figure 1 in [40] provides EBSDbased inverse pole figure grain maps coupled with pole figures for the starting $\mathrm{Nb}$ and $\mathrm{Zr}$ material used in this study.

The ARB process involves stacking plates of material and performing a single-pass room temperature rolling reduction ( $\sim 5 \%)$ to bond the initially separate sheets. The $\mathrm{Zr}$ and $\mathrm{Nb}$ plates, after initial processing, were cleaned in an ultrasonic acetone bath and then wire brushed with a $76 \mathrm{~mm}$ diameter wheel of fine stainless steel bristles rotating at 1200 revolutions per minute. This surface preparation, repeated prior to all ARB steps, served to minimize retained oxide within the microstructure as well as to promote bonding between the layers by removing the native oxide and enhancing the surface roughness. The $\mathrm{Zr}$ and $\mathrm{Nb}$ sheets were stacked and then roll bonded via a single high-strain rolling pass on a 2-high rolling mill (Waterbury-Farrel) with $457.2 \mathrm{~mm}$ diameter rolls and a strain rate of $\sim 50 \mathrm{~mm} / \mathrm{mm}^{*} \mathrm{sec}$. Mill settings during roll bonding were chosen in order to achieve a target of $50 \%$ reduction in overall sample thickness. Due to differing amount of work hardening present in each sample, however, actual reductions ranged from 40-60\%. After successful roll bonding, the plate was cut in half and stacked such that the process could be repeated. In this way, material was fabricated that had various nominal layer thicknesses and various amounts of accumulated strain. In addition, the $\mathrm{Zr}$ and $\mathrm{Nb}$ sheets were initially stacked in a $\mathrm{Zr}-\mathrm{Nb}-\mathrm{Zr}$ sandwich with a $\mathrm{Nb}$ sheet of $2 \mathrm{~mm}$ and $\mathrm{Zr}$ sheets of $1 \mathrm{~mm}$. The $\mathrm{Zr}-\mathrm{Nb}$ interface bond was created only during the first pass and all subsequent 
bonding steps were $\mathrm{Zr}$ on $\mathrm{Zr}$. This means that any retained oxide along the initial $\mathrm{Zr}$ - $\mathrm{Nb}$ interface was then spread over kilometers of interfacial length during the roll bonding process.

Intermediate annealing treatments were conducted in order to minimize the occurrence of shear bands. Static anneals at $575^{\circ} \mathrm{C}$ for 60 minutes under vacuum followed by furnace cooling were performed after every second roll bonding pass or at strain intervals of $\sim 1.4$. The time and temperature combination was chosen in order to minimize intermixing of the $\mathrm{Zr}$ and $\mathrm{Nb}$ which may be expected to occur above temperatures of around $\sim 500^{\circ} \mathrm{C}[59]$.

Characterization via diffraction was performed after both roll bonding steps and annealing treatments. Although roll bonding/restacking steps and annealing treatments were performed between $h=676 \mathrm{~nm}$ and $h=92 \mathrm{~nm}$, material was not removed for characterization in order to conserve material for further roll bonding steps. Table 1 provides the layer thicknesses and total strain associated with each sample that was investigated in this study. Due to the initial $\mathrm{Zr}-\mathrm{Nb}-\mathrm{Zr}$ stacking sequence, the average layer thickness, $h$, reported in Table 1 represents the nominal layer thickness for all layers except the two surface layers of $\mathrm{Zr}_{2}$ which are approximately $h / 2$. Total strain was calculated via equation (1):

$\varepsilon=\ln \frac{h_{0}}{h}$

Table 1. Number of layers, layer thickness, total strain and latest processing step for the material characterized through NeD. A (^) indicates processing steps where material was not retained for characterization.

\begin{tabular}{|c|l|l|l|}
\hline Number of Layers & $\begin{array}{l}\text { Average Layer } \\
\text { Thickness, } h, \text { um }\end{array}$ & Total Strain, $\varepsilon$ & Latest Processing Step \\
\hline 2 & 845 & 0.9 & Roll Bonding \\
\hline 4 & 466 & 1.5 & Roll Bonding \\
\hline 4 & 466 & 1.5 & Annealing \\
\hline
\end{tabular}




\begin{tabular}{|c|c|c|c|}
\hline 8 & 198 & 2.3 & Roll Bonding \\
\hline 16 & 106 & 2.9 & Roll Bonding \\
\hline 16 & 106 & 2.9 & Annealing \\
\hline 32 & 59 & 3.5 & Roll Bonding \\
\hline 64 & 26 & 4.3 & Roll Bonding \\
\hline 64 & 26 & 4.3 & Annealing \\
\hline 128 & 12 & 5.1 & Roll Bonding \\
\hline 256 & 6 & 5.8 & Roll Bonding \\
\hline 256 & 6 & 5.8 & Annealing \\
\hline 512 & 3 & 6.5 & Roll Bonding \\
\hline 1024 & 1.5 & 7.2 & Roll Bonding \\
\hline 1024 & 1.5 & 7.2 & Annealing \\
\hline 2048 & 0.676 & 8.0 & Roll Bonding \\
\hline $4096^{\wedge}$ & 0.372 & 8.6 & Roll Bonding \\
\hline $4096^{\wedge}$ & 0.372 & 8.6 & Annealing \\
\hline $8192^{\wedge}$ & 0.155 & 9.5 & Roll Bonding \\
\hline 16384 & 0.092 & 10.0 & Roll Bonding \\
\hline
\end{tabular}

NeD was performed on both the initial materials and processed samples using the High Pressure Preferred Orientation (HIPPO) neutron time-of-flight diffractometer at the Los Alamos Neutron Science Center at Los Alamos National Laboratory (LANL) $[60,61]$. Unlike X-ray diffraction or EBSD, NeD provides a bulk measurement of specimen texture. The techniques used for both the collection of NeD data and the accompanying analysis to capture phase-specific orientation distribution functions (ODFs) was consistent with those described in [14]. A small change within the HIPPO diffractometer set-up is 
the addition of two new detector panels at $2 \theta=60^{\circ}$ and $120^{\circ}$. The samples for which bulk textures for $\mathrm{Nb}$ and $\mathrm{Zr}$ within the composite were measured are listed in Table 1.

Transmission electron microscopy (TEM) was used in order to investigate the planarity of the interfaces and confirm the nominal thickness of the layers when $h=92 \mathrm{~nm}$. Chemical sharpness of the interfaces at this length scale was explored in a previous publication [43] and indicated that the interfaces were chemically sharp, despite the mechanical straining and intermediate annealing treatments. Bright Field TEM was performed using a Tecnai F30 (FEI, Hillsboro, OR, USA) electron microscope operating at $300 \mathrm{kV}$ on cross-sectional samples viewed along the transverse direction (TD). The samples were prepared using a Helios Nanolab DualBeam (FEI, Hillsboro, OR, USA) Focused Ion Beam (FIB). A traditional approach of tripod polishing, dimpling, and ion milling lead to damage in the $\mathrm{Zr}$ layers that prevented successful characterization. In this case, FIB lift-outs were extracted from a plan view section of the composite. Prior to extraction a chemical polish of $25 \mathrm{ml}$ lactic acid, $15 \mathrm{ml}$ of $\mathrm{HNO}_{3}$, and $5 \mathrm{ml} \mathrm{HF}$ was applied for an extended period of time in order to remove surface layers damaged during previous preparation steps.

\section{Experimental Results and Discussion:}

\section{Microstructure:}

Figure 1 shows electron microscopy results of the $h=92 \mathrm{~nm} \mathrm{Zr-Nb}$ sample. Selected area diffraction patterns such as the one shown in Figure $1 \mathrm{~b}$ indicate that the hcp crystal structure of Zr was maintained during fabrication. Figure 1c presents a scanning transmission electron microscopy (STEM) bright field image with phase boundaries overlaid in red based on the corresponding high angle annular dark field image (not shown). Figure 1c clearly shows that the lamellar structure is maintained, though signs of non-homogenous deformation are present such as variations in layer thickness. It is also observed in Fig. 1c that, despite the fine nanoscale dimensions, grain boundaries are present within both the $\mathrm{Zr}$ and $\mathrm{Nb}$ layers. The relatively thin layers tend to have a single grain through the thickness 
whereas the relatively thicker layers tend to have multiple grains through the layer thickness. In the bright field TEM diffraction contrast image in Fig. 1a, significant dislocation-based contrast is evident within both $\mathrm{Zr}$ and $\mathrm{Nb}$. The frequency of grain boundaries and stored dislocation content within the grains is much higher than in nanostructured ARB Cu-Nb multilayers strained to approximately the same h [53].

As stated earlier, due to the intermittent annealing treatments, shear bands did not form in this material and this is confirmed by optical microcopy [40]. Although shear banding is suppressed, interface roughening is observed. Interface roughening is not limited to the $\mathrm{Zr}$ - $\mathrm{Nb}$ material system and has been observed in the $\mathrm{Cu}-\mathrm{Nb}, \mathrm{Cu}-\mathrm{Zn}$, and $\mathrm{Cu} / \mathrm{Zn} / \mathrm{Al}$ systems $[14,16,62]$ and is predicted in two-phase crystal plasticity finite element calculations $[47,63,64]$.

\section{Texture evolution:}

$\mathrm{Nb}$ phase in the composite: An $\alpha$-fiber plot for the $\mathrm{Nb}$ phase within the composite is shown in Figure 2 for varying layer thicknesses and processing steps. The $\alpha$-fiber is a characteristic fiber for rolled body centered cubic $(\mathrm{BCC})$ materials that is comprised of orientations that share the $\langle 110\rangle$ crystal axis parallel to the rolling direction (RD).

Generally we find that the most significant layer size effect is the Nb texture is weak for all $h \geq$ $1.5 \mu \mathrm{m}$ but noticeably stronger for $\mathrm{h}=92 \mathrm{~nm}$. For $h \geq 1.5 \mu \mathrm{m}$, very small peaks in intensity are found for the $\{001\},\{113\}$, and $\{334\}$ orientations. The $h=92 \mathrm{~nm}$ as-rolled sample, however, exhibits a more intense $\alpha$-fiber containing a relatively strong peak at the $\{001\}<1 \overline{1} 0>$ orientation and two minor peaks at $\{115)<1 \overline{1} 0>$ and near $\{334\}<1 \overline{1} 0>$.

Figure 2 shows the corresponding $\gamma$-fiber plot for the $\mathrm{Nb}$ phase within the composite. The $\gamma$-fiber plot provides ODF intensity data for orientations with the $\{111\}$ parallel to the normal direction (ND) of the sample. Like the $\alpha$-fiber, the $\psi$-fiber is weak for $h \geq 1.5 \mu \mathrm{m}$ but is more intense for $h=92 \mathrm{~nm}$. 
Comparing the $\alpha$ and $y$-fibers in the as-rolled (AR) and annealed (AN) samples reveals that annealing had very little effect on the texture. This may be expected, as the melting temperature of $\mathrm{Nb}$ is high relative to the temperature of the intermediate static annealing steps. However, in prior works, a strengthening of the $\mathrm{\gamma}$-fiber during similar annealing treatments of $\mathrm{Nb}$ has been reported [65]. As Fig. 2 shows, such a strengthening of the $\gamma$-fiber is not seen in this study.

Comparison with textures in the literature: Figure 3 compares the $\alpha$ and $\gamma$ fibers of the resulting texture in the $\mathrm{Nb}$ phase at $h=92 \mathrm{~nm}$ with those of other rolled or roll-bonded $\mathrm{Nb}$ textures reported in the literature $[14,40,45]$. Of these reported textures, one is the rolled single-phase $\mathrm{Nb}$ in [45] and another is the $\mathrm{Nb}$ phase texture within the roll-bonded $\mathrm{Zr}-\mathrm{Nb}$ with $\mathrm{h}=4 \mathrm{um}$, which was made without intermediate annealing steps [40]. These two Nb textures are similar to each other but different than the $\mathrm{Nb}$ texture within the coarse- and fine-layered $\mathrm{Zr}$-Nb composites made here. To compare with another nanolayered $\mathrm{Nb}$ phase, we also provide the $\mathrm{Nb}$ phase texture within the rollbonded $\mathrm{Cu}-\mathrm{Nb}$ at $h=86 \mathrm{~nm}$ that also had undergone intermittent annealing treatments [14]. Unlike the $\mathrm{Nb}$ phase texture in the ARB $\mathrm{Zr}-\mathrm{Nb}$, the $\mathrm{Nb}$ phase texture in the ARB Cu-Nb contains a peak near the $\{112\}<1 \overline{1} 0>$ orientation.

The $\mathrm{Nb}$ phase textures within the present $\mathrm{Zr}-\mathrm{Nb}$ samples at all $\mathrm{h}$ are significantly different than these three other $\mathrm{Nb}$ textures. For instance, in all the other cases, the $\{001\}<1 \overline{1} 0>$ component diminished and the $\{112\}<1 \overline{1} 0>$ or a component near it strengthened with increasing strain. In contrast, in the $\mathrm{Nb}$ phase texture in the present $\mathrm{Zr}-\mathrm{Nb}$ composite the most intense component in the $\alpha$ fiber was the $\{001\}<1 \overline{1} 0>$ component and the $\{112\}<1 \overline{1} 0>$ component did not strengthen as the strain increased. It may be that the deformation mechanisms operating during rolling in the $\mathrm{Nb}$ phase within the present composites deviate from those expected in these other $\mathrm{Nb}$ based systems. Later, we investigate using crystal plasticity the slip activity associated with the development of the $\mathrm{Nb}$ texture. 
$\mathrm{Zr}$ phase in the composite: Figure 4 shows the measured $\langle 11 \overline{2} 0\rangle$ and $\langle 10 \overline{1} 0\rangle$ fibers for the $\mathrm{Zr}$ phase within composites of different layer thickness. As $h$ was reduced from $106 \mu \mathrm{m}$ to $92 \mathrm{~nm}$, the texture strengthened, becoming peaked at two components. In Fig. 4 a for the $\langle 11 \overline{2} 0\rangle$ fiber, a peak

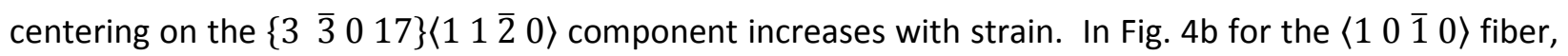

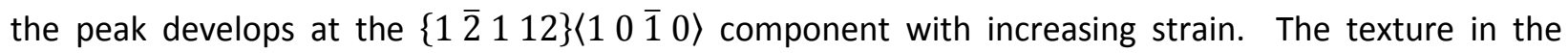
nanolayered composite is remarkably sharp.

The fiber plots for the $\mathrm{h}=26 \mathrm{um}$ and $\mathrm{h}=1.5 \mathrm{um}$ after static annealing are also shown in order to assess the effect of annealing on texture. For the thicker $h=26$ um sample, we observe that annealing affects the texture, shifting the peak from the $\left\{\begin{array}{llll}3 & \overline{3} & 0 & 17\end{array}\right\}\left\langle\begin{array}{llll}1 & 1 & \overline{2} & 0\rangle\end{array}\right.$ component to the $\left\{\begin{array}{llll}7 & \overline{7} & 0 & 24\end{array}\right\}\langle 11 \overline{2} 0\rangle$ component along the $\langle 11 \overline{2} 0\rangle$ fiber. This result is consistent with the observations of Jiang et al. [44] on single-phase rolled $\mathrm{Zr}$. There it was shown that annealing at over $600^{\circ} \mathrm{C}$ leads to a similar shift in the $\langle 11 \overline{2} 0\rangle$ fiber. In addition, we also observe a noticeable change in the $\langle 10 \overline{1} 0\rangle$ fiber, namely a peak shift

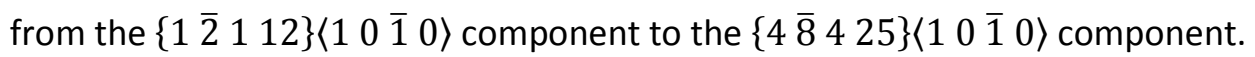

Most interestingly, we find that the peak shift caused by annealing in the coarser layer 26 um is not apparent in the finer layer $1.5 \mathrm{um}$. From the two fiber plots, we see that annealing this finer layer sample weakened the overall $\alpha$ fiber texture. A similar length-scale dependent hindrance of recrystallization at similar layer thicknesses between 1-2 um was reported in the $\mathrm{Cu}$ phase of a $\mathrm{Cu}-\mathrm{Nb}$ layered composite produced by ARB [66]. There it was linked to either the noticeable reduction in dislocation density seen in $\mathrm{Cu}$ at 1-2 um layers or interface constraints. Given the significant dislocation content observed in the $\mathrm{Zr}$ phase in Figure $1 \mathrm{a}$, it could be that suppression of certain recrystallization effects on texture at this 1-2 um length scale is due to layer constraint.

Comparison with textures in the literature: Figure 5 compares the texture for $\mathrm{Zr}$ in this study at $h=92 \mathrm{~nm}$ with a previously reported texture for $\mathrm{Zr}$ in a roll bonded $\mathrm{Zr}$-Nb composite with 4 um layers fabricated without intermediate annealing treatments [40]. Quantitative texture comparisons in this 
paper are limited to prior $\mathrm{Zr}-\mathrm{Nb}$ results due to the inadequacy of pole figures and inverse pole figures

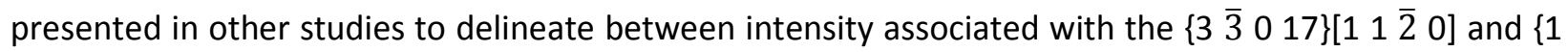
$\begin{array}{llll}\overline{2} & 12\}\end{array}\left[\begin{array}{llll}1 & 0 & \overline{1} & 0\end{array}\right]$ peaks. The $\mathrm{Zr}$ phase textures of this study, both the coarse-layered and the nanolayered (92 nm), develop very different textures. First, from Fig. 5, we clearly see that the Zr phase texture from

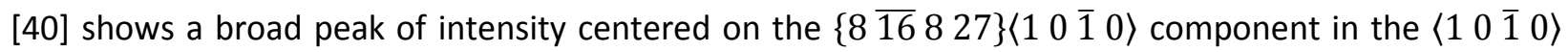
fiber and little to no intensity along the $\langle 11 \overline{2} 0\rangle$ fiber. Second, the texture developed in the $92 \mathrm{~nm}$ composite is distinctively much more peaked that previously reported $\mathrm{Zr}$ textures. Thus, we would expect that the deformation mechanisms operating in the $\mathrm{Zr}$ - $\mathrm{Nb}$ composites made here (with intermediate annealing plus roll bonding) are different than those in conventionally rolled polycrystalline $\mathrm{Zr}$, particularly as the layer thickness reduces to the nanoscale. We explore this hypothesis in the modeling section.

Interfacial Analysis:

Figure 6 provides inverse pole figures (IPFs) for both $\mathrm{Zr}$ and $\mathrm{Nb}$ measured via $\mathrm{NeD}$ at $h=92 \mathrm{~nm}$ in the as-rolled condition. As the interfaces are relatively planar and perpendicular with the sample ND, the ND IPF can be utilized as an estimate of the interface plane normal distribution.

Consistent with the rolled monolithic $\mathrm{Zr}$ in [44] and the TEM micrograph of the $\mathrm{Zr}$ phase in the

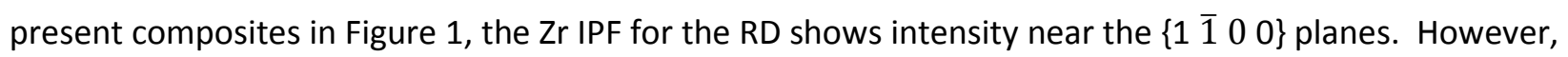
unlike the texture of the monolithic Zr, the IPF for the ND shows a band of intensity at approximately $15^{\circ}$ from the $\{0001\}$ planes and not $25^{\circ}$ away as seen in [44]. This significant difference is sufficient to indicate a possible change in deformation mechanisms.

In Nb, two peaks dominate the ND IPF intensity $-\{100\}$ and $\{111\}$. These features point to

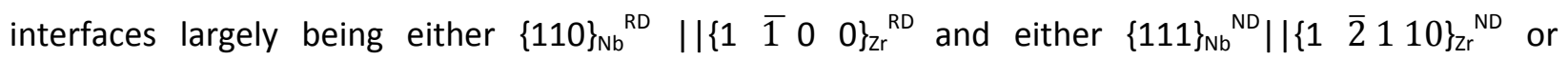

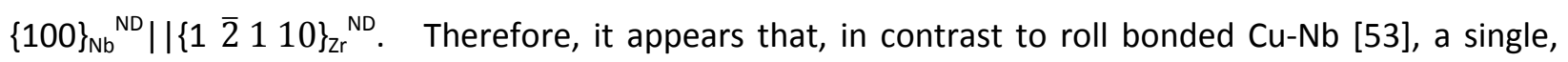
stable interface has not developed in $\mathrm{Zr}-\mathrm{Nb}$ at $\mathrm{h}=92 \mathrm{~nm}$. Nonetheless, considering the strong textures 
in both $\mathrm{Zr}$ and $\mathrm{Nb}$, the distribution of interface characters could be narrow and thus $\mathrm{Zr}-\mathrm{Nb}$ could be useful as another material system to apply theories of stable interfaces under extreme straining [67].

\section{Polycrystal Modeling:}

The neutron diffraction indicates two interesting results: 1 ) the texture of the $\mathrm{Nb}$ phase in the present $\mathrm{Zr}$ - $\mathrm{Nb}$ nanoscale composites differs noticeably from the textures of $\mathrm{Nb}$ in other material systems deformed in similar ways and 2) a significant transition in the texture of the $\mathrm{Zr}$ phase as the material is refined from micron-layer thicknesses to nanolayer thicknesses. We suspect that these changes could be signatures of deviations in slip activities from those expected or reported previously. To explore this possibility, the viscoplastic self-consistent (VPSC) crystal plasticity polycrystal model is used to relate dislocation slip activity to the texture development observed in the $\mathrm{Zr}$ and $\mathrm{Nb}$ polycrystalline phases within the present composite [40]. This model does not account for the effects of the Zr-Nb interface and therefore cannot reveal the role the interface plays in texture evolution. It also does not account for intermediate annealing steps. Despite these limitations, the model can be useful, at least as a first step, in determining the active slip systems and their relative activity needed to attain the observed textures.

\section{Modeling methodology:}

In brief, VPSC is a mean-field polycrystal formulation $[50,68]$. It represents a polycrystal as a group of grain orientations with a distinct orientation and volume fraction. In calculation, each grain orientation is modeled as an ellipsoidal inclusion embedded in a homogeneous effective medium (HEM) with average properties of the polycrystal. Like most polycrystal models, it accounts for orientation and hardening evolution on each slip system within each grain. Unlike simpler upper and lower bound mean-field polycrystal models, such as Taylor, Relaxed constraints, and Sachs [69]; however, VPSC accounts for the evolution of grain shape.

Important assumptions when utilizing the model are selecting which slip systems are made available for crystallographic slip and how dislocation hardening evolves in these slip systems. It has 
been shown that in conventional coarse-grained $\mathrm{Zr}$ and $\mathrm{Zr}$ alloys, slip occurs most often on the prismatic $<a>$ and pyramidal $<c+a>$ slip systems $[50,70,71]$, and at large strains basal $<a>$ slip systems can be additionally activated $[39,48]$. Here, these three modes are made available to the $\mathrm{Zr}$ crystals. In $\mathrm{Nb}$, slip occurs most often on the $\{110\}<111>$ and $\{112\}<111>$ slip systems $[72,73]$ and these were made available to $\mathrm{Nb}$. We will refer to these systems, respectively, in short as $\{110\}$ and $\{112\}$ slip.

In this work, the hardening laws for each slip system in each phase are based on thermally activated dislocation motion and vary as a function of temperature and strain rate [50]. In this hardening model, denoted the DD model, the evolution of dislocation density (DD) is different for each slip mode and is governed by material parameters such as Peierls stress, activation energy for depinning locked dislocations, and dislocation trapping rates.

Table 2 Material parameters for evolution of slip resistance in the coarse-grained $\mathrm{Zr}$ phase [50].

\begin{tabular}{|c|c|c|c|}
\hline$\alpha$-slip mode & $\begin{array}{c}\text { prismatic slip } \\
\alpha=1\end{array}$ & $\begin{array}{c}\text { basal slip } \\
\alpha=2\end{array}$ & $\begin{array}{c}\text { pyramidal slip } \\
\alpha=3\end{array}$ \\
\hline$\tau_{o, f}^{\alpha}[\mathrm{MPa}]$ & 20 & 700 & 160 \\
\hline$k_{1}^{\alpha}\left[\mathrm{m}^{-1}\right]$ & $1.25 \times 10^{8}$ & $1.25 \times 10^{10}$ & $2.25 \times 10^{8}$ \\
\hline$g^{\alpha}$ & $3.75 \times 10^{-3}$ & $3.675 \times 10^{-2}$ & $6.5 \times 10^{-2}$ \\
\hline$D^{\alpha}[\mathrm{MPa}]$ & 330 & 330 & 100 \\
\hline$\dot{\varepsilon}_{o}^{\alpha}\left(s^{-1}\right)$ & $10^{7}$ & $10^{7}$ & $10^{7}$ \\
\hline$q^{\alpha}[\mathrm{MPa}]$ & 88 & 0 & 0 \\
\hline$H^{\alpha}[\mathrm{MPa}]$ & 100 & 100 & 170 \\
\hline
\end{tabular}

For the Zr phase the DD model material parameters for the three slip modes, $\alpha$ : prismatic $(\alpha=1)$, basal $(\alpha=2)$, and pyramidal slip ( $\alpha=3)$, were established earlier in [50] and are given in Table 2 . These achieved good agreement with the textures seen in rolled monolithic $\mathrm{Zr}$ and the coarse-layered (4 um) Zr phase in a straight-roll-bonded Zr-Nb composite. In the table, $\tau_{o, f}^{s}$ is the initial friction stress, $\mathrm{H}^{\alpha}$ is a Hall-Petch-like constant, $\dot{\varepsilon}_{o}$ is a reference strain rate, $g^{\alpha}$ is an effective activation enthalpy, $D^{\alpha}$ is a 
drag stress, and $q^{\alpha}$ is a dislocation recovery rate coefficient defining the fraction of $\alpha$-type dislocations that do not annihilate but become substructure.

In bcc metals, many recent studies have demonstrated the importance of non-Schmid effects on the motion of dislocations belonging to the $\{110\}$ and $\{112\}$ slip systems [74-76]. For the Nb phase, we make use of a modified hardening law that introduces non-Schmid effects into the DD model [77]. While the material parameters we use have been characterized for the particular $\mathrm{Nb}$ composition studied here [40], the extra parameters associated with the non-Schmid effects were not altered from those used previously for a Ta-W alloy. This simplification was done primarily due to a lack of data and evidence suggesting that these parameters would not depend sensitively on material details. The DD material parameters used for both $\{110\}$ and $\{112\}$ slip systems in the coarse-grained $\mathrm{Nb}$ phase are given in Table 3. The assumption of equal resistances to $\{110\}$ and $\{112\}$ slip will be addressed in the results.

Table 3 - Constitutive parameters for evolution of slip resistance in the $\mathrm{Nb}$ phase [40].

\begin{tabular}{|c|c|}
\hline$\alpha$-slip mode & $\{110\} \&\{112\}$ slip \\
\hline$\tau_{o, f}^{\alpha}[\mathrm{MPa}]$ & 135 \\
\hline$k_{1}^{\alpha}\left[\mathrm{m}^{-1}\right]$ & $4.4 \times 10^{8}$ \\
\hline$g^{\alpha}$ & $3.5 \times 10^{-2}$ \\
\hline$D^{\alpha}[\mathrm{MPa}]$ & 210 \\
\hline$\dot{\varepsilon}_{o}^{\alpha}\left(s^{-1}\right)$ & $10^{7}$ \\
\hline$q^{\alpha}[\mathrm{MPa}]$ & 14 \\
\hline$H^{\alpha}[\mathrm{MPa}]$ & 50 \\
\hline
\end{tabular}

Deformation twinning in either phase takes place at colder temperatures than the room temperature used here [78]. As it is not observed in significant fraction (> 1-5\%) in the $\mathrm{Zr}$ and $\mathrm{Nb}$ phases in postdeformation TEM and EBSD analyses, its contribution is neglected in the model calculations.

Finally, in all VPSC calculations, we use boundary conditions of plane strain compression, an idealization of rolling that best applies to the center of the material, and apply low strain rates at room temperature to match laboratory conditions [47]. In the model, the texture is initialized using the measured starting texture (Fig. 1 in in [40]). Reduction of Zr-Nb layer thickness for modeling of the nano- 
grained material was from $1.5 \mu \mathrm{m}$ to $92 \mathrm{~nm}$. In all calculations, the simulations were carried out to 0.6 strain.

\section{Modeling Results and Discussion:}

Comparison with Simulated VPSC-Based Nb Textures: Figure 7 compares the $\alpha$ and $\gamma$-fibers for the Nb phase in the present $\mathrm{Zr}-\mathrm{Nb}$ nanocomposite sample with $\mathrm{h}=92 \mathrm{~nm}$ with the VPSC simulation. The model predicts both the $\gamma$-fiber and $\alpha$-fiber reasonably well. It captures the higher intensity of the $\{001\}<1 \overline{1} 0>$ component and the less intense peak near the $\{334\}<1 \overline{1} 0>$ component. To compare the textures, Fig. 8 shows the $\{001\},\{011\}$, and $\{111\}$ pole figures from the measurement and the VPSC calculation. Good agreement is again achieved. From these calculations, it is possible to extract the average slip activity, which is related to the number and distribution of slip shear on the active systems for each grain, averaged over all the grains in the polycrystal. As shown, the relative activities of $\{110\}$ and $\{112\}$ slip are similar with $\{110\}$ slip being slightly more active (Fig. 8c).

Two aspects are worth noting. First, we find that predicted texture evolution corresponds to multi-slip conditions inside the grains. Thus, multi-slip still persists in nano-sized crystals. This result is consistent with the dense dislocation structures seen in the TEM analysis (Fig. 1). Second, good agreement is also achieved when the initial slip resistance for $\{110\}$ slip increases to $145 \mathrm{MPa}$. This change only makes $\{112\}$ slip a little less active than $\{110\}$ slip. Thus, it appears that the Nb phase texture is associated with more or less similar contributions from both $\{110\}$ and $\{112\}$ slip.

Comparison with Simulated VPSC-Based Zr Textures: Figure 5 compares the measured $\langle 11 \overline{2} 0\rangle$ and $\langle 10 \overline{1} 0\rangle$ fibers at $h=92 \mathrm{~nm}$ with two VPSC simulations. Figures 9 and 10 make the same comparison for the entire textures using $\{0001\},\{10 \overline{1} 0\},\{11 \overline{2} 0\}$ pole figures and for the $\phi_{2}=0$ and $30^{\circ}$ ODF sections. In one simulation (labeled Sim. All Systems Active), we use the parameters in Table 2, which provides a texture characteristic of rolled $\mathrm{Zr}$ and roll-bonded $\mathrm{Zr}$ in a coarse-layered $\mathrm{Zr}$ - $\mathrm{Nb}$ composite [40]. The measurement of the latter sample is also shown in Fig. 5 and it can be seen that this VPSC simulation 


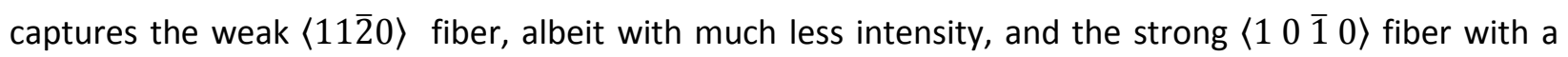
peak at the $\{8 \overline{16} 827\}\langle 10 \overline{1} 0\rangle$ component. The corresponding slip activity is given in Figure $8 \mathrm{e}$. Prismatic slip is the most active, followed by pyramidal slip. As straining proceeds, prismatic and pyramidal slip harden, which is seen to promote basal slip. The amount of basal slip predicted (reaching 25\%), although uncommonly large for Zr, is still consistent with other studies of Zr deformed to large strains $[39,79]$. However, as noted before, the $\mathrm{Zr}$ in the present $92 \mathrm{~nm}$ nanocomposite develops a strikingly different texture than straight-rolled $\mathrm{Zr}$ and straight roll-bonded $\mathrm{Zr}$. This difference suggests that the slip activity in the $92 \mathrm{~nm}$ composite is likely different than that shown in Figure 8e.

Figure 5 compares a second VPSC simulation (labeled Sim. SPIB) where the initial slip resistances for pyramidal slip and basal slip were altered (to 1400 and $400 \mathrm{MPa}$, respectively), such that the pyramidal slip was nearly suppressed and the basal slip significantly enhanced. Figures $9 a, b$ and $10 a, b$ show the same comparison respectively in the form of the $\phi_{2}=0$ and $30^{\circ}$ ODF sections and pole figures.

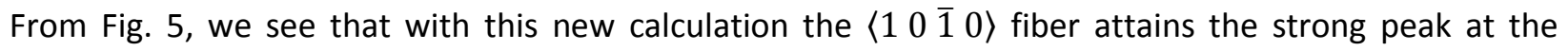

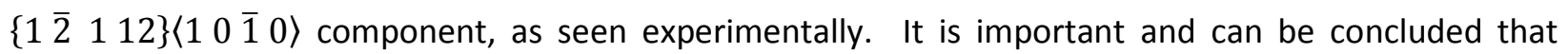

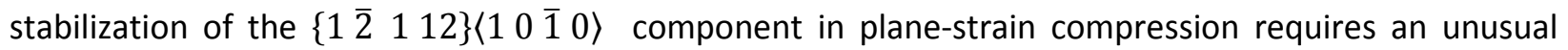
predominance of prismatic and basal slip with pyramidal suppressed.

The VPSC simulations do not explain the occurrence of the large peak at the $\left\{\begin{array}{llll}3 & \overline{3} & 0 & 17\end{array}\right\}\left\langle\begin{array}{llll}1 & 1 & \overline{2} & 0\end{array}\right)$ component in the $\langle 11 \overline{2} 0\rangle$ fiber, particularly prominent in the nanoscale composite. In the calculation, the $\langle 11 \overline{2} 0\rangle$ fiber was not as strong and stable. Since our VPSC simulations do not include the effects of intermediate annealing treatments, it may be inferred that the observed stability of this component could be a result of annealing. Prior work on ARB of monolithic $\mathrm{Zr}$ [44] found that annealing is responsible for a rotation of peak intensity to this component in the $\langle 11 \overline{2} 0\rangle$ fiber. To gain insight on whether annealing was involved, we carried out VPSC simulations starting with an annealed texture at 1.5 um with the predominant $\left\{\begin{array}{llll}3 & \overline{3} & 0 & 17\end{array}\right\}\left\langle\begin{array}{llll}1 & 1 & \overline{2} & 0\rangle\end{array}\right.$ component. However the calculations find that the 
slip induced under plane-strain compression destabilizes this orientation. Therefore, it is doubtful that the persistence of this orientation should be attributed to intermediate annealing. It is more likely a consequence of the interface, which would have a growing influence as layer thickness decreases.

The foregoing analysis provides some hints that the interface affects texture development. At the fine length scales and high interface densities associated with nanolayer thicknesses, it is reasonable to think the influence of the interface is enhanced. It has been proposed, for instance, in fcc-bcc composites that the bimetal interface can influence slip and twinning activity in several ways, such as via nucleation and transmission of certain slip systems [80, 81] and twinning systems [78], geometric constraints [80], kinematic constraints associated with co-deformation [46] and its formation energy [67]. Many of these studies are carried out using atomic-scale simulations [78, 82-84], involving small numbers of dislocations and short time scales, and thus it is not straightforward to translate these results to texture evolution. Some attempts have been made to incorporate such dislocation-interface interactions into larger scale polycrystalline plasticity models, like VPSC or 3D full-field spatially resolved techniques, such as crystal plasticity finite element $[46,47,85-87]$. Only very recently has CPFE been extended to examine the effect of slip transmission on texture evolution [88]. Clearly more effort in this area of interface-driven slip activity and texture evolution is needed. At present, we can only speculate that the stabilization of predominant $\left\{\begin{array}{llll}1 & 1 & \overline{2} & 10\end{array}\right\}\langle 11 \overline{2} 0\rangle$ component with strain in the nanoscale composite could be due to kinematic constraints at the hcp/bcc interface that become more prominent as the interface density increases and/or local shear components.

\section{Conclusions:}

In this study, we investigated the texture evolution of a $\mathrm{Zr}$-Nb nanolayered composite processed via accumulative roll bonding. Average individual nanoscale layer thicknesses of $92 \mathrm{~nm}$ were achieved via severe plastic deformation (over strains of 10 ) and intermediate static annealing steps between roll- 
bonding steps. The lamellar structure was maintained, the $\mathrm{Zr}$ phase remained hcp, and the interfaces were relatively sharp. The main conclusions of this work are:

1. Using neutron diffraction we show that the as rolled textures of the $\mathrm{Zr}$ and $\mathrm{Nb}$ phases within the composite deviated from those observed in $\mathrm{Zr}$ [58] and $\mathrm{Nb}$ [55] when rolled separately, in $\mathrm{Nb}$ in accumulative roll bonded $\mathrm{Cu}-\mathrm{Nb}$ [14], and in the $\mathrm{Zr}$ and $\mathrm{Nb}$ phases within accumulative roll bonded $\mathrm{Zr}-\mathrm{Nb}$ without an intermittent annealing treatment [64].

2. We observed a marked increase in the intensity of the $\mathrm{Nb}$ phase texture of the $h=92 \mathrm{~nm}$ composite that was not seen in the coarser micron-layered composites. The $h=92 \mathrm{~nm}$ as-rolled sample exhibited an intense $\alpha$-fiber containing a relatively strong peak at $\{001\}<1 \overline{1} 0>$ orientation and two minor peaks at $\{115)<1 \overline{1} 0>$ and near $\{334\}<1 \overline{1} 0>$.

3. The Zr phase texture of the $h=92 \mathrm{~nm}$ composite developed a noticeably sharp texture with two

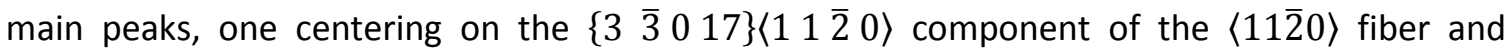

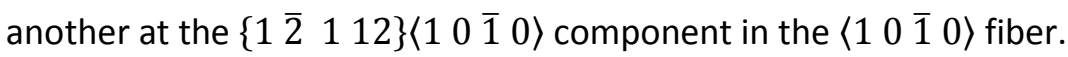

4. A dislocation density based hardening model with non-Schmid effects was implemented into the polycrystal visco-plastic self-consistent scheme (DD-VPSC) to associate the active deformation slip modes with texture development. The model suggested that the $\mathrm{Nb}$ phase texture in the 92 $\mathrm{nm}$ composite is associated with multiple slip and similar contributions from $\{110\}<111>$ and $\{112\}<111>$ slip.

5. The DD+VPSC model was also applied to the $\mathrm{Zr}$ phase. The model suggested that the predominant $\left\{\begin{array}{llll}1 & \overline{2} & 1 & 12\end{array}\right\}\langle 10 \overline{1} 0\rangle$ component can be attributed to an unusual slip activity of prismatic and basal slip with little to no pyramidal slip in plane-strain compression.

6. Analysis of the inverse pole figures for the $\mathrm{Zr}-\mathrm{Nb}$ nanocomposite with $h=92 \mathrm{~nm}$ suggested that a few interface characters may predominate: $\{110\}_{\mathrm{Nb}}^{\mathrm{RD}} \|\{1 \overline{100}\}_{\mathrm{Zr}}^{\mathrm{RD}}$ and either $\{111\}_{\mathrm{Nb}}{ }^{\mathrm{ND}} \|\{1$

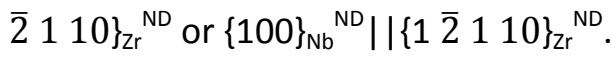




\section{Acknowledgements:}

This work was supported in part by the Center for Materials at Irradiation and Mechanical Extremes, an Energy Frontier Research Center funded by the U.S. Department of Energy, Office of Science, Office of Basic Energy Sciences under Award Number 2008LANL1026. This work was also supported in part by the Los Alamos National Laboratory Directed Research and Development (LDRD) project 20140348ER. This work was performed, in part, at the Center for Integrated Nanotechnologies, an Office of Science User Facility operated for the U.S. Department of Energy (DOE) Office of Science. Los Alamos National Laboratory, an affirmative action equal opportunity employer, is operated by Los Alamos National Security, LLC, for the National Nuclear Security Administration of the U.S. Department of Energy under contract DE-AC52-06NA25396. Neutron diffraction results were collected on the High Pressure Preferred Orientation (HIPPO) beam line at the Los Alamos Neutron Science Center. Electron microscopy was performed at the Los Alamos Electron Microscopy Laboratory.

\section{Figure Captions:}

Figure 1: (a) TEM-Based diffraction contrast image of Zr-Nb multilayer when $h=92 \mathrm{~nm}$. (b) Selected area diffraction shows that the $\mathrm{Zr}$ phase is highly textured and consistent with the NeD texture. (c) BF STEM image of Zr-Nb layers with contrast showing grain boundaries within layers. Red lines indicate phase boundaries which were determined by complimentary HAADF STEM.

Figure 2: Fiber plots for $\alpha$ and $\gamma$ fibers for $\mathrm{Nb}$ for varying layer thicknesses and processing history. For coarser layers $(h \geq 1.5 \mu \mathrm{m})$ little to no change in texture is observed between roll bonding or annealing steps. The observed texture is inconsistent with that of rolled $\mathrm{Nb}$ [45]. At $h=92 \mathrm{~nm}$, a sharp peak is present at $\{001\}<110>$ with other peaks at $\{115\}<110>$ and $\{334\}<110>$. For comparison, the ODF intensity associated with the $\{112\}<110>\mathrm{Nb}$ peak for ARB Cu-Nb at similar length scales was 15 [14]. 
Figure 3: $\alpha$ and $\gamma$ fiber plot for $\mathrm{Nb}$ from the $\mathrm{Zr}-\mathrm{Nb}$ material at $h=92 \mathrm{~nm}$ in this study compared with literature. $\mathrm{Nb}$ in non-annealed $\mathrm{Zr}-\mathrm{Nb}$, annealed $\mathrm{Cu}-\mathrm{Nb}$ and rolled single phase $\mathrm{Nb}$ all show a peak in intensity near the $\{112\}<1 \overline{1} 0>$ orientation. $\mathrm{Nb}$ in annealed $\mathrm{Zr}-\mathrm{Nb}$, shows a more complex array of peaks.

Figure 4: Fiber plots for Zr for varying layer thicknesses and processing steps. (a) $\langle 11 \overline{2} 0\rangle$ fiber plot. At coarser layers (106 and $26 \mu \mathrm{m}$ ) annealing leads to a reduction in $\left\{\begin{array}{llll}3 & -3 & 17\end{array}\right\} 11-20>$ component and an

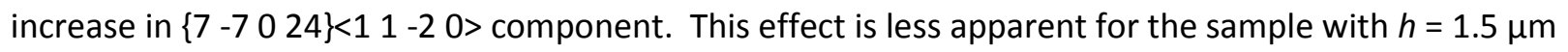
annealed. Roll bonding steps exaggerate the $\left\{\begin{array}{lllll}3 & -3 & 0 & 17\end{array}\right\}<1 \quad-2 \quad 0>$ component at the expense of both

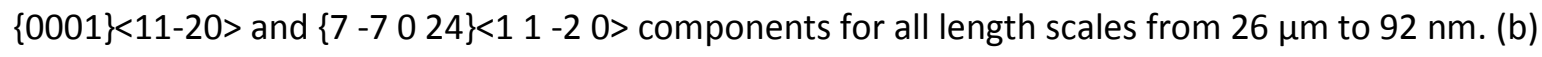

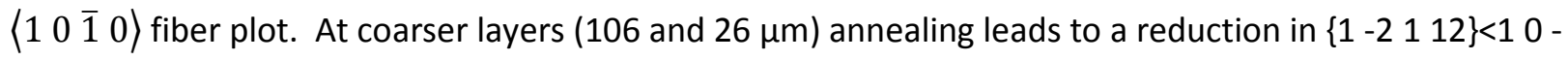
$10>$ component and an increase in $\left\{\begin{array}{l}4-8425\}<1 \\ 0\end{array}-10>\right.$ component. This effect is less apparent for the sample with $h=1.5 \mu \mathrm{m}$ annealed. Roll bonding steps exaggerate the $\left\{\begin{array}{lll}1-2 & 1 & 12\end{array}<10-10>\right.$ component at the expense of both $\{0001\}<10-10>$ and $\left\{\begin{array}{l}4-8 \\ 4\end{array} 25\right\}<10-10>$ components for all length scales from 26 $\mu \mathrm{m}$ to $92 \mathrm{~nm}$.

Figure 5: Fiber plots for Zr compared with literature and simulations. (a) $\langle 11 \overline{2} 0\rangle$ fiber plot. For Zr-Nb without annealing and VPSC-based simulations (which do not include annealing), $\left\{\begin{array}{llll}3-3 & 0 & 17\end{array}\right\}<\begin{array}{lll}1 & -2 & 0\end{array}$ texture is not observed to the level seen in this study. (b) $\left\langle\begin{array}{llll}1 & 0 & \overline{1} & 0\end{array}\right)$ fiber plot. Zr-Nb without annealing

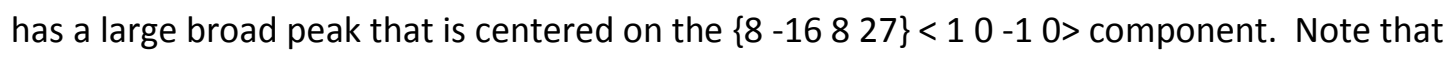
suppressing pyramidal slip coupled with increased basal slip (SPIB) improves the VPSC fit along the $<10$ $10>$ fiber for the $Z r$ in this study. When all slip systems are active, VPSC performs well in matching the Zr texture along the $<10-10>$ fiber for Zr-Nb without annealing.

Figure 6: IPFs for $\mathrm{Zr}$ (top row) and $\mathrm{Nb}$ (bottom row) for $h=92 \mathrm{~nm}$. RD, TD, and ND refer to the sample direction with ND providing an estimate of the interface plane normal distribution. 
Figure 7: $\alpha$ and $\gamma$ fiber plot for $\mathrm{Nb}$ from the $\mathrm{Zr}-\mathrm{Nb}$ material at $h=92 \mathrm{~nm}$ compared with VPSC simulation results.

Figure 8: Pole figure representations of (a) NeD results for $\mathrm{Nb}$ in $\mathrm{Zr}-\mathrm{Nb}$ at $h=92 \mathrm{~nm}$, (b) VPSC simulation results for slip activity as shown in (c).

Figure 9: ODF slices for $\mathrm{Zr}$ based on (a) NeD results for $\mathrm{Zr}$ in $\mathrm{Zr}-\mathrm{Nb}$ at $h=92 \mathrm{~nm}$, (b) VPSC-based simulation results with pyramidal slip activity suppressed and increased basal activity as seen in (d), (c) simulation results for slip activity as shown in (e), (d) slip activity as a function of strain for the VPSC simulation with suppressed pyramidal activity and increased basal slip activity (SPIB). (e) slip activity as a function of strain for the VPSC with all systems active.

Figure 10: Pole figure representations of (a) NeD results for $\mathrm{Zr}$ in $\mathrm{Zr}-\mathrm{Nb}$ at $h=92 \mathrm{~nm}$, (b) VPSC-based simulation results with pyramidal slip activity suppressed and basal slip increased as shown in Figure 9(d), (c) Simulation results for slip activity as shown in Figure 9(e).

\section{References:}

[1] Clemens BM, Kung H, Barnett SA. Mrs Bulletin 1999;24:20.

[2] Mara NA, Bhattacharyya D, Dickerson P, Hoagland RG, Misra A. Applied Physics Letters 2008;92.

[3] Misra A, Verdier M, Lu YC, Kung H, Mitchell TE, Nastasi N, Embury JD. Scripta Materialia 1998;39:555.

[4] Misra A, Hoagland RG. Journal of Materials Research 2005;20:2046.

[5] Bellou A, Scudiero L, Bahr DF. Journal of Materials Science 2010;45:354.

[6] Han WZ, Misra A, Mara NA, Germann TC, Baldwin JK, Shimada T, Luo SN. Philosophical Magazine 2011;91:4172.

[7] Wei QM, Li N, Mara N, Nastasi M, Misra A. Acta Materialia 2011;59:6331.

[8] Zhernenkov M, Jablin MS, Misra A, Nastasi M, Wang Y, Demkowicz MJ, Baldwin JK, Majewski J. Applied Physics Letters 2011;98.

[9] Saito Y, Utsunomiya H, Tsuji N, Sakai T. Acta Materialia 1999;47:579.

[10] Qu P, Zhou L, Xu H, Acoff VL. Metallurgical and Materials Transactions a-Physical Metallurgy and Materials Science 2014;45A:6217.

[11] Yasuna K, Terauchi M, Otsuki A, Ishihara KN, Shingu PH. Materials Science and Engineering aStructural Materials Properties Microstructure and Processing 2000;285:412.

[12] Ghalandari L, Moshksar MM. Journal of Alloys and Compounds 2010;506:172.

[13] Eslami AH, Zebarjad SM, Moshksar MM. Materials Science and Technology 2013;29:1000. 
[14] Carpenter JS, Vogel SC, LeDonne JE, Hammon DL, Beyerlein IJ, Mara NA. Acta Materialia 2012;60:1576.

[15] Dehsorkhi RN, Qods F, Tajally M. Materials Science and Engineering a-Structural Materials Properties Microstructure and Processing 2011;530:63.

[16] Ghalandari L, Mandavian MM, Reihanian M. Materials Science and Engineering a-Structural Materials Properties Microstructure and Processing 2014;593:145.

[17] Sun YF, Tsuji N, Fujii H, Li FS. Journal of Alloys and Compounds 2010;504:S443.

[18] Chang H, Zheng MY, Xu C, Fan GD, Brokmeier HG, Wu K. Materials Science and Engineering aStructural Materials Properties Microstructure and Processing 2012;543:249.

[19] Chang H, Zheng M, Gan W, Xu C, Brokmeier HG. Rare Metal Materials and Engineering 2013;42:441.

[20] Yang D, Cizek P, Hodgson P, Wen Ce. Scripta Materialia 2010;62:321.

[21] Carpenter JS, Nizolek TJ, McCabe RJ, Zheng SJ, Scott JE, Vogel SC, Mara NA, Pollock TM, Beyerlein IJ. Materials Research Letters 2014:1.

[22] Perez-Prado MT, del Valle JA, Ruano OA. Scripta Materialia 2004;51:1093.

[23] Perez-Prado MT, Gimazov AA, Ruano OA, Kassner ME, Zhilyaev AP. Scripta Materialia 2008;58:219.

[24] Perez-Prado MT, Zhilyaev AP. Physical Review Letters 2009;102.

[25] Manna I, Chattopadhyay PP, Banhart F, Fecht HJ. Applied Physics Letters 2002;81:4136.

[26] Liao XZ, Zhou F, Lavernia EJ, He DW, Zhu YT. Applied Physics Letters 2003;83:5062.

[27] Zhou F, Liao XZ, Zhu YT, Dallek S, Lavernia EJ. Acta Materialia 2003;51:2777.

[28] Huang JY, Liao XZ, Zhu YT, Zhou F, Lavernia EJ. Philosophical Magazine 2003;83:1407.

[29] Liao XZ, Huang JY, Zhu YT, Zhou F, Lavernia EJ. Philosophical Magazine 2003;83:3065.

[30] Zhu YT, Liao XZ, Wu XL. Progress in Materials Science 2012;57:1.

[31] Beyerlein IJ, Capolungo L, Yapici GG, Tome CN, Karaman I. Materials Science Forum 2010;633634:483.

[32] Popov AA, Pyshmintsev IY, Demakov SL, Illarionov AG, Lowe TC, Sergeyeva AV, Valiev RZ. Scripta Materialia 1997;37:1089.

[33] Sergueeva AV, Stolyarov VV, Valiev RZ, Mukherjee AK. Scripta Materialia 2001;45:747.

[34] Terada D, Inoue S, Tsuji N. Journal of Materials Science 2007;42:1673.

[35] Milner JL, Abu-Farha F, Bunget C, Kurfess T, Hammond VH. Materials Science and Engineering aStructural Materials Properties Microstructure and Processing 2013;561:109.

[36] del Valle JA, Perez-Prado MT, Ruano OA. Materials Science and Engineering a-Structural Materials Properties Microstructure and Processing 2005;410:353.

[37] Perez-Prado MT, del Valle JA, Ruano OA. Materials Letters 2005;59:3299.

[38] Ma A, Jiang J, Saito N, Shigematsu I, Yuan Y, Yang D, Nishida Y. Materials Science and Engineering a-Structural Materials Properties Microstructure and Processing 2009;513-14:122.

[39] Yapici GG, Tome CN, Beyerlein IJ, Karaman I, Vogel SC, Liu C. Acta Materialia 2009;57:4855.

[40] Knezevic M, Nizolek T, Ardeljan M, Beyerlein IJ, Mara N, Pollock TM. International Journal of Plasticity 2014;57:16.

[41] Edalati K, Horita Z, Yagi S, Matsubara E. Materials Science and Engineering a-Structural Materials Properties Microstructure and Processing 2009;523:277.

[42] Kassner ME, Perez Prado MT, Hayes TA, Jiang L, Barrabes SR, Lee IF. Journal of Materials Science 2013;48:4492.

[43] Jiang L, Ruano OA, Kassner ME, Perez-Prado MT. Jom 2007;59:42.

[44] Jiang L, Perez-Prado MT, Gruber PA, Arzt E, Ruano OA, Kassner ME. Acta Materialia 2008;56:1228.

[45] Raabe D, Ball J, Gottstein G. Scripta Metallurgica Et Materialia 1992;27:211. 
[46] Mayeur JR, Beyerlein IJ, Bronkhorst CA, Mourad HM, Hansen BL. International Journal of Plasticity 2013;48:72.

[47] Hansen BL, Carpenter JS, Sintay SD, Bronkhorst CA, McCabe RJ, Mayeur JR, Mourad HM, Beyerlein IJ, Mara NA, Chen SR, Gray GT, III. International Journal of Plasticity 2013;49:71.

[48] Knezevic M, Beyerlein IJ, Nizolek T, Mara N, Pollock TM. Materials Research Letters 2014;1:133.

[49] Proust G, Kaschner GC, Beyerlein IJ, Clausen B, Brown DW, McCabe RJ, Tome CN. Experimental Mechanics 2010;50:125.

[50] Beyerlein IJ, McCabe RJ, Tome CN. International Journal for Multiscale Computational Engineering 2011;9:459.

[51] Valiev R. Nature Materials 2004;3:511.

[52] Valiev RZ, Langdon TG. Metallurgical and Materials Transactions a-Physical Metallurgy and Materials Science 2011;42A:2942.

[53] Carpenter JS, McCabe RJ, Zheng SJ, Wynn TA, Mara NA, Beyerlein IJ. Metallurgical and Materials Transactions A 2014;45:2192.

[54] Zheng S, Beyerlein IJ, Carpenter JS, Kang K, Wang J, Han W, Mara NA. Nature Communications 2013;4.

[55] Raabe D, Lucke K. Zeitschrift Fur Metallkunde 1994;85:302.

[56] Raabe D, Hangen U. Journal of Materials Research 1995;10:3050.

[57] Raabe D, Hangen U. Materials Letters 1995;22:155.

[58] Cerreta E, Gray GT, Hixson RS, Rigg PA, Brown DW. Acta Materialia 2005;53:1751.

[59] Massalski TB, Okamoto H. Binary Alloy Phase Diagrams: ASM International, 1990.

[60] Wenk HR, Lutterotti L, Vogel S. Nuclear Instruments \& Methods in Physics Research Section aAccelerators Spectrometers Detectors and Associated Equipment 2003;515:575.

[61] Vogel SC, Hartig C, Lutterotti L, Von Dreele RB, Wenk HR, Williams DJ. Powder Diffraction 2004;19:65.

[62] Mahdavian MM, Ghalandari L, Reihanian M. Materials Science and Engineering a-Structural Materials Properties Microstructure and Processing 2013;579:99.

[63] Mayeur JR, Beyerlein IJ, Bronkhorst CA, Mourad HM. Materials 2014;7:302.

[64] Ardeljan M, Knezevic M, Nizolek T, Beyerlein IJ, Zheng SJ, Carpenter JS, McCabe RJ, Mara NA, Pollock TM. IOP Conference Series: Materials Science and Engineering 2014;63:012170 (24 pp.).

[65] Jiang H, Bieler TR, Compton C, Grimm TL. Physica C-Superconductivity and Its Applications 2006;441:118.

[66] Lim SCV, Rollett AD. Materials Science and Engineering a-Structural Materials Properties Microstructure and Processing 2009;520:189.

[67] Beyerlein IJ, Mayeur JR, Zheng SJ, Mara NA, Wang J, Misra A. Proceedings of the National Academy of Sciences 2014;111:4386.

[68] Lebensohn RA, Tome CN. Acta Metallurgica Et Materialia 1993;41:2611.

[69] Kocks UF, Tome CN, Wenk HR. Texture and Anisotropy: Preferred Orientations in Polycrystals and their Effects on Materials Properties. Cambridge, UK: Cambridge University Press, 1998.

[70] Partridge PG. Metallurgical Reviews 1967;12:169.

[71] Tome CN, Maudlin PJ, Lebensohn RA, Kaschner GC. Acta Materialia 2001;49:3085.

[72] Franciosi P. Acta Metallurgica 1983;31:1331.

[73] Franciosi P. Acta Metallurgica 1985;33:1601.

[74] Ito K. Philosophical Magazine a-Physics of Condensed Matter Structure Defects and Mechanical Properties 2001;81:1387.

[75] Qing Q, Bassani JL. Journal of the Mechanics and Physics of Solids 1992;40:835.

[76] Dao M, Asaro RJ. Materials Science and Engineering a-Structural Materials Properties Microstructure and Processing 1993;170:143. 
[77] Knezevic M, Beyerlein IJ, Lovato ML, Tome CN, Richards AW, McCabe RJ. International Journal of Plasticity 2014;62:93.

[78] Beyerlein IJ, Zhang X, Misra A. Annual Reviews in Materials Research 2014;44:329.

[79] Xu F, Holt RA, Daymond MR. Journal of Nuclear Materials 2008;373:217.

[80] Beyerlein IJ, Wang J, Kang K, Zheng SJ, Mara N. Materials Research Letters 2014;1:89.

[81] Beyerlein IJ, Wang J, Zhang R. Acta Materialia 2013;61:7488.

[82] Beyerlein IJ, Caro A, Demkowicz MJ, Mara NA, Misra A, Uberuaga BP. Materials Today 2013;16:443.

[83] Martinez E, Caro A, Beyerlein IJ. Physical Review B 2014;90:054103.

[84] Mara NA, Beyerlein IJ. Journal of Materials Science A 2014;49:6497.

[85] Beyerlein IJ, McCabe RJ, Tome CN. Journal of the Mechanics and Physics of Solids 2011;59:988.

[86] Roters F, Eisenlohr P, Hantcherli L, Tjahjanto DD, Bieler TR, Raabe D. Acta Materialia 2010;58:1152.

[87] Ardeljan M, Beyerlein IJ, Knezevic M. Journal of the Mechanics and Physics of Solids 2014;66:16.

[88] Mayeur JR, Beyerlein IJ, Bronkhorst CA, Mourad HM. International Journal of Plasticity 2015;65:206. 
(a)

)
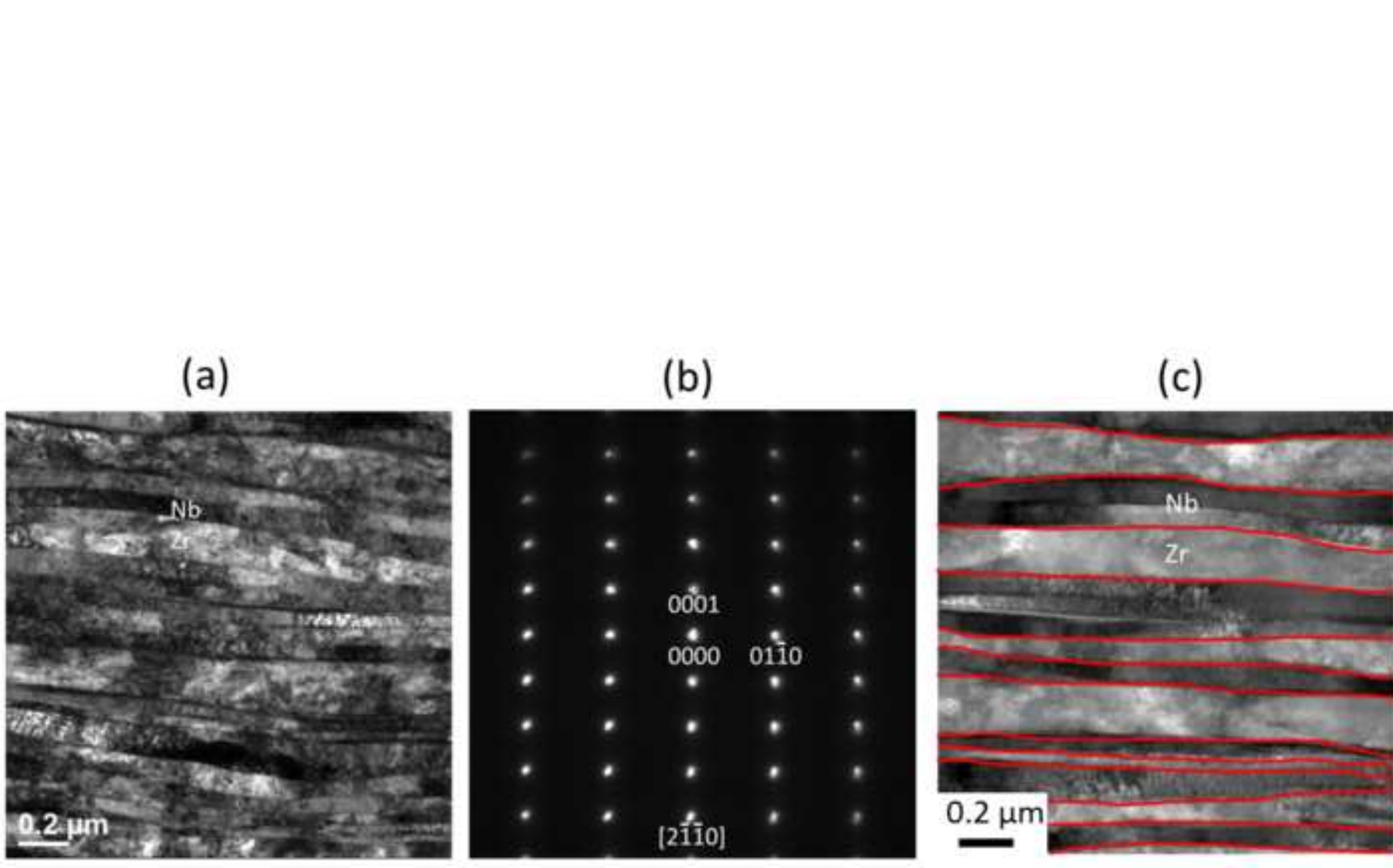

(c)

$0.2 \mu \mathrm{m}$

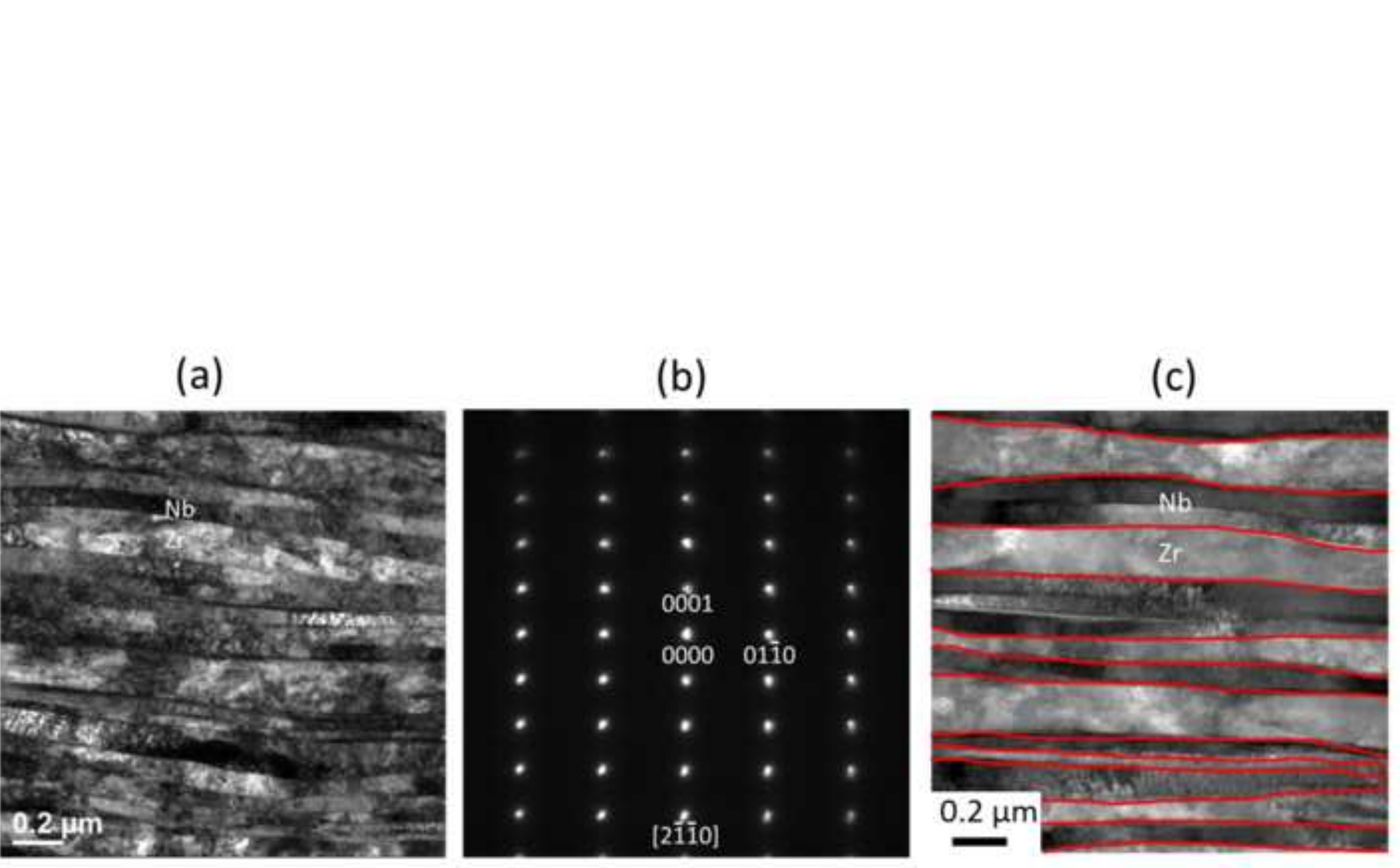

(b)
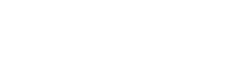

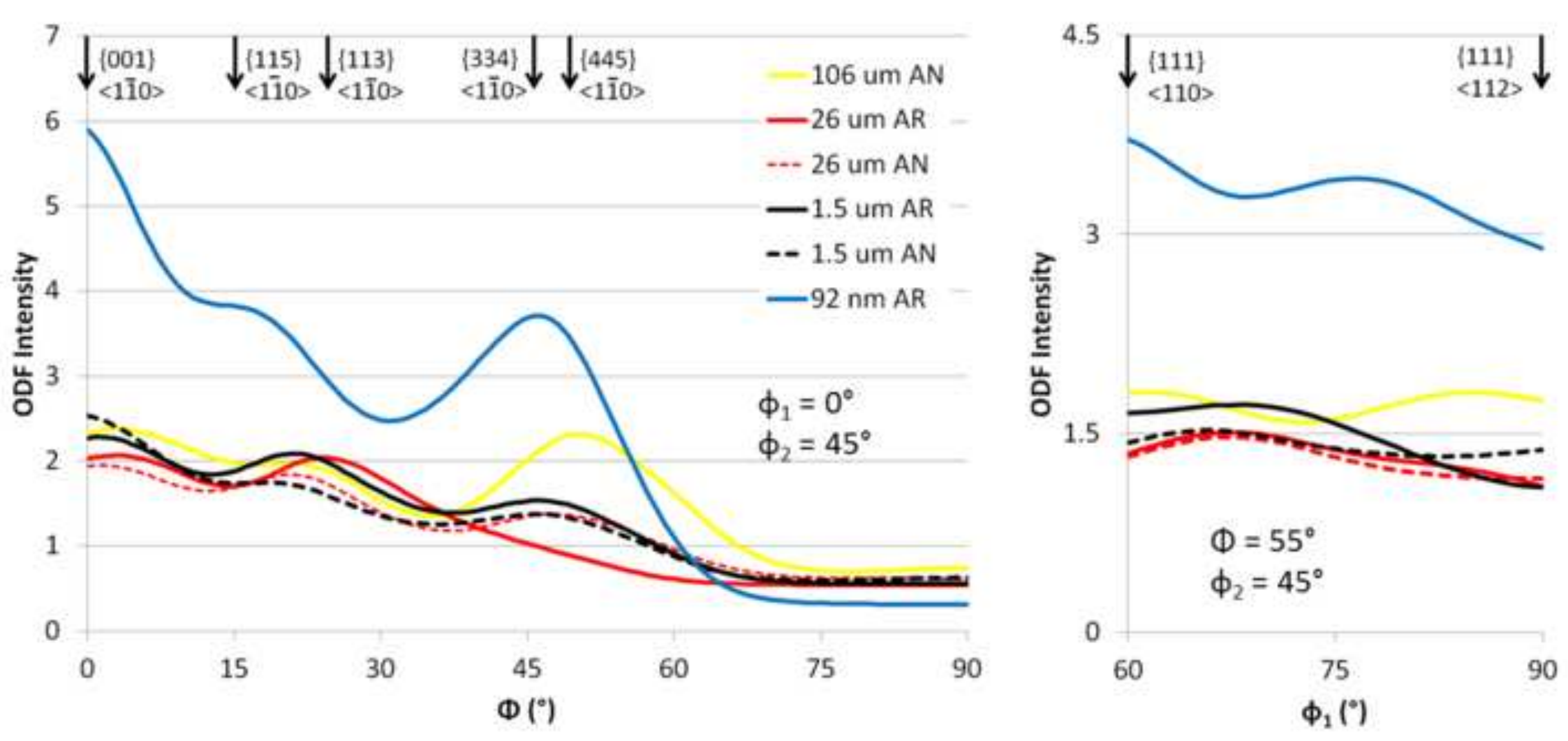

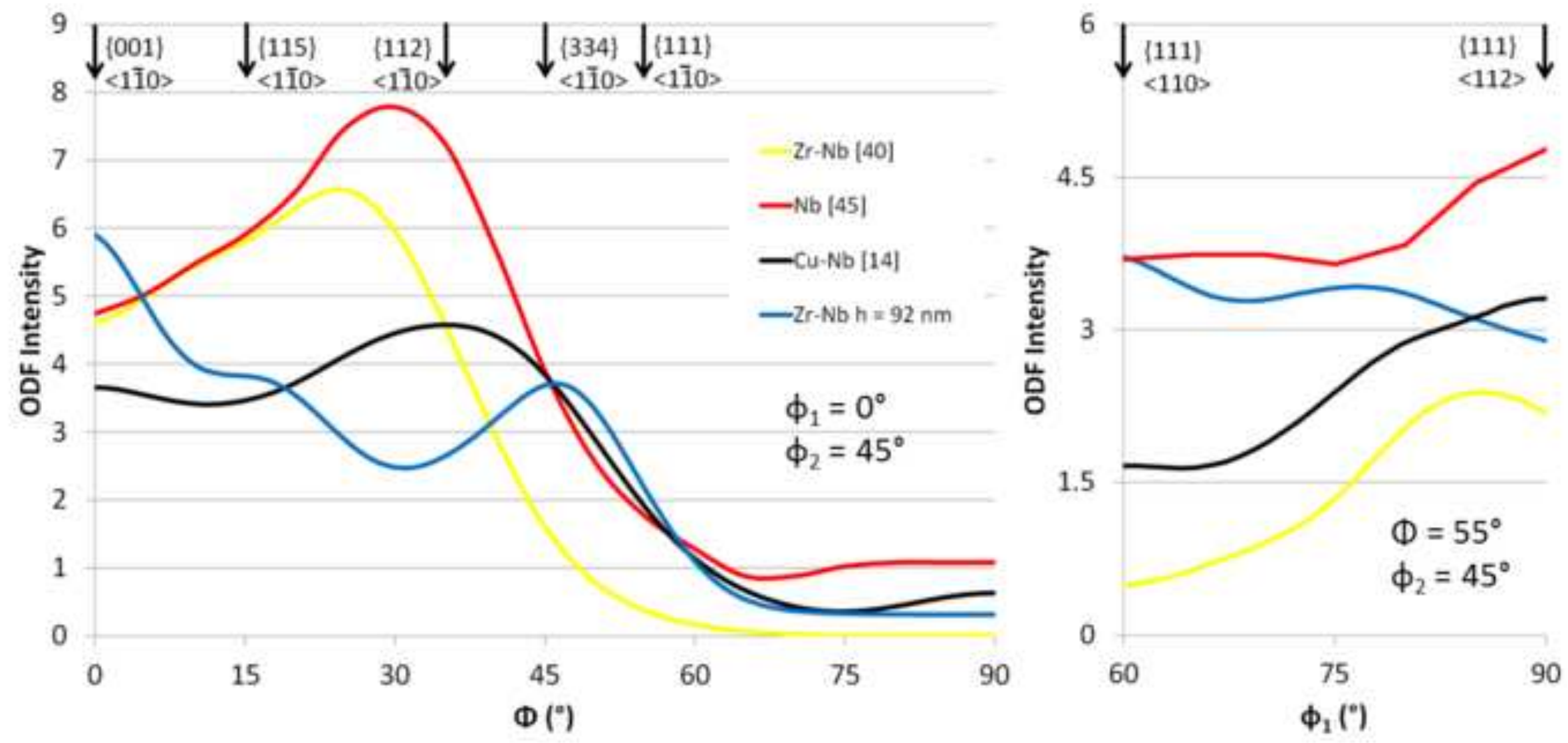
(a)

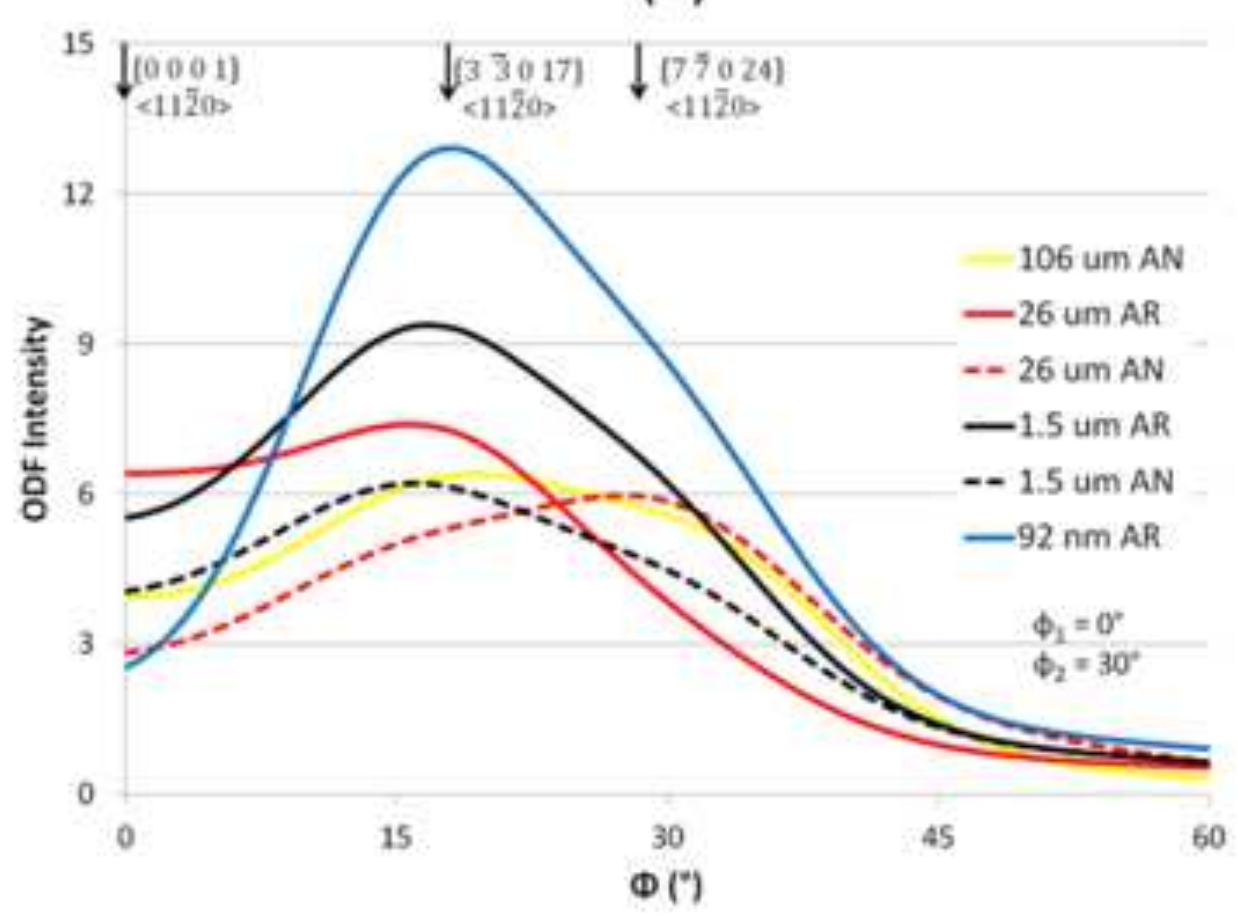

(b)

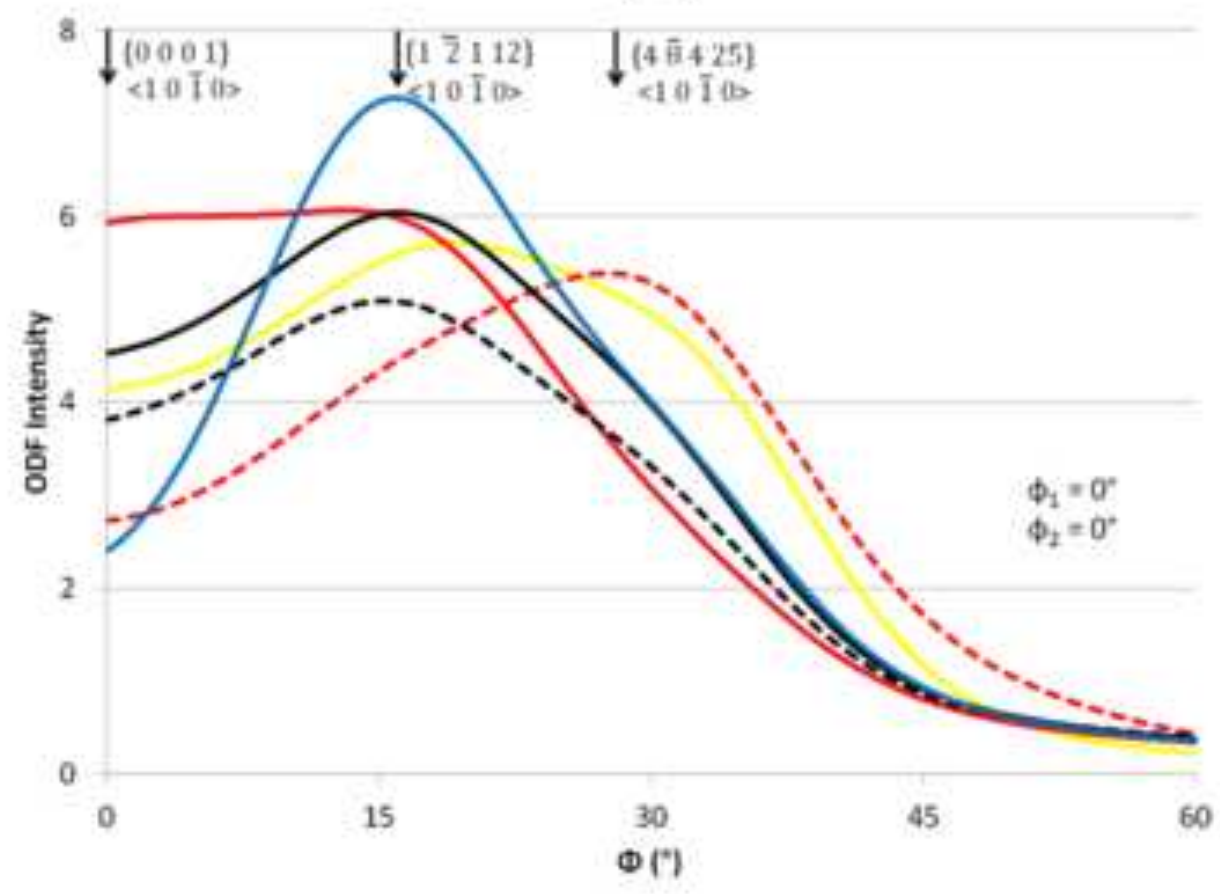


(a)

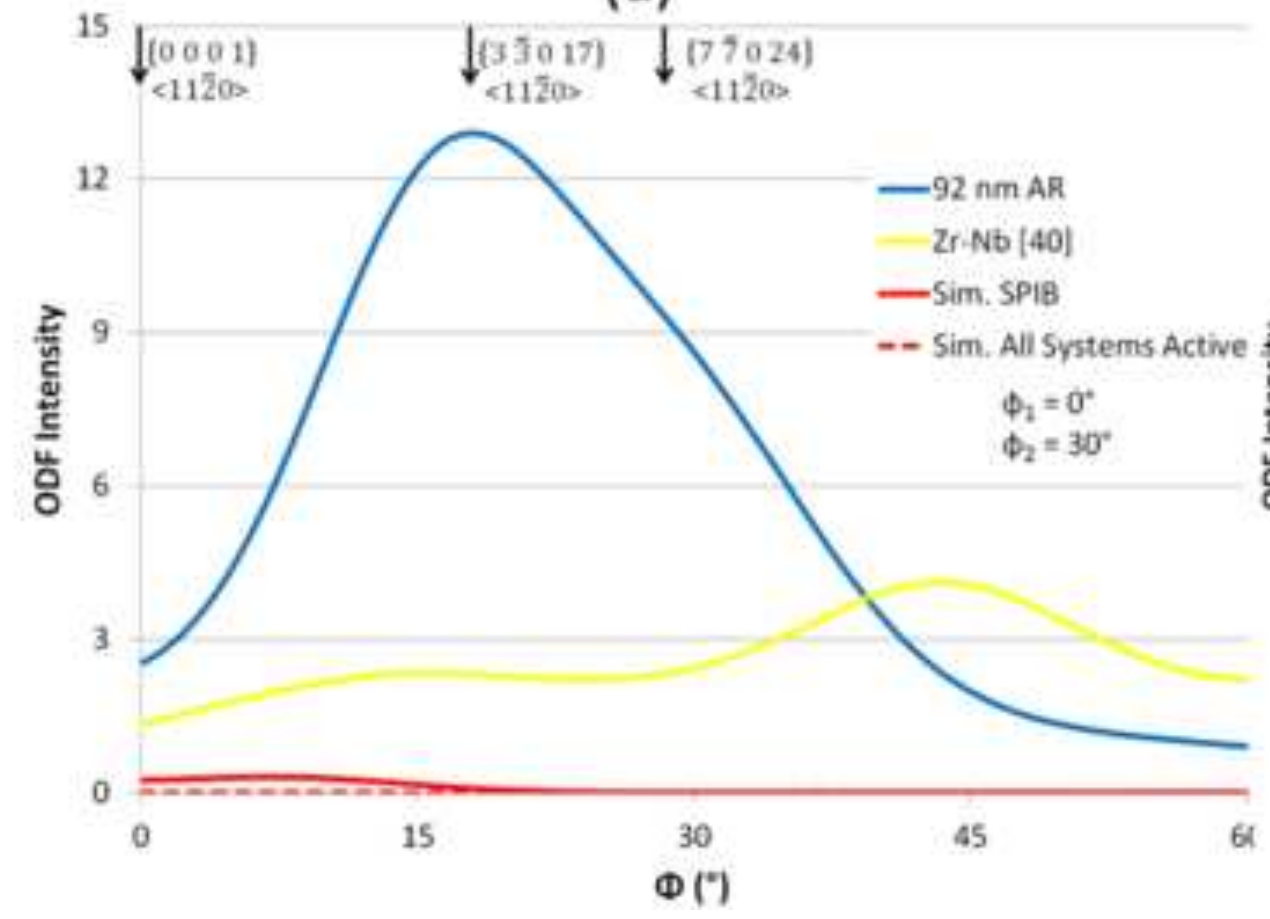

(b)

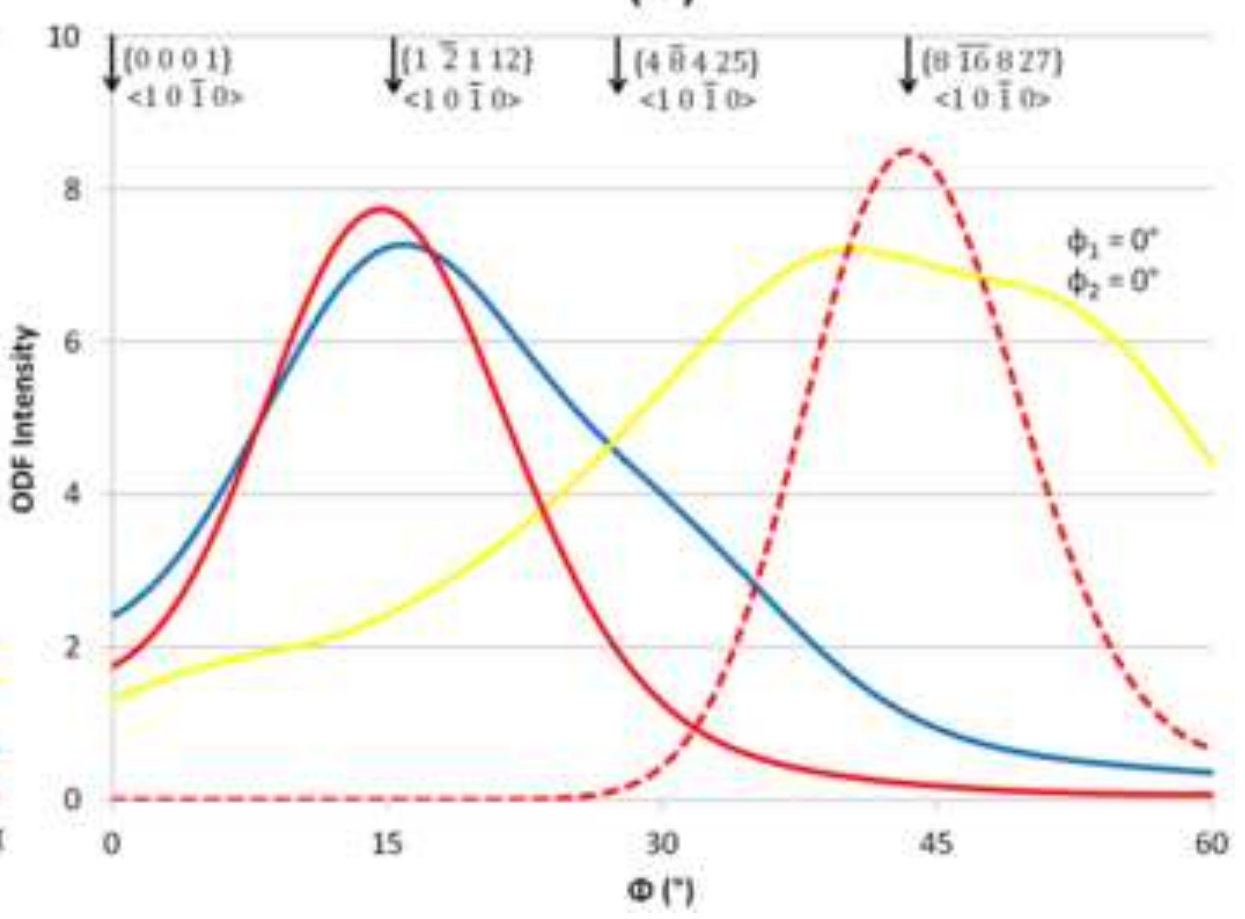



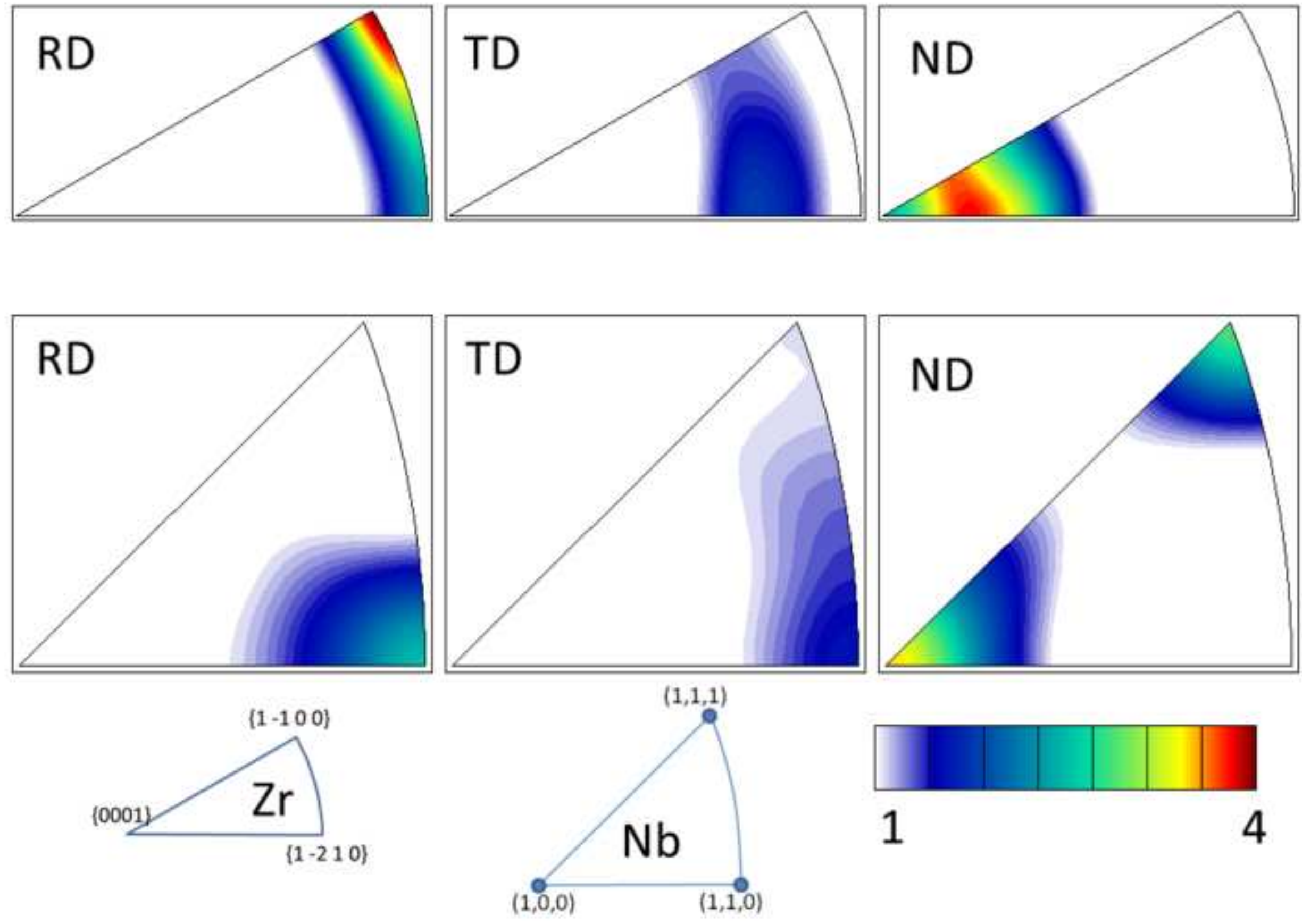

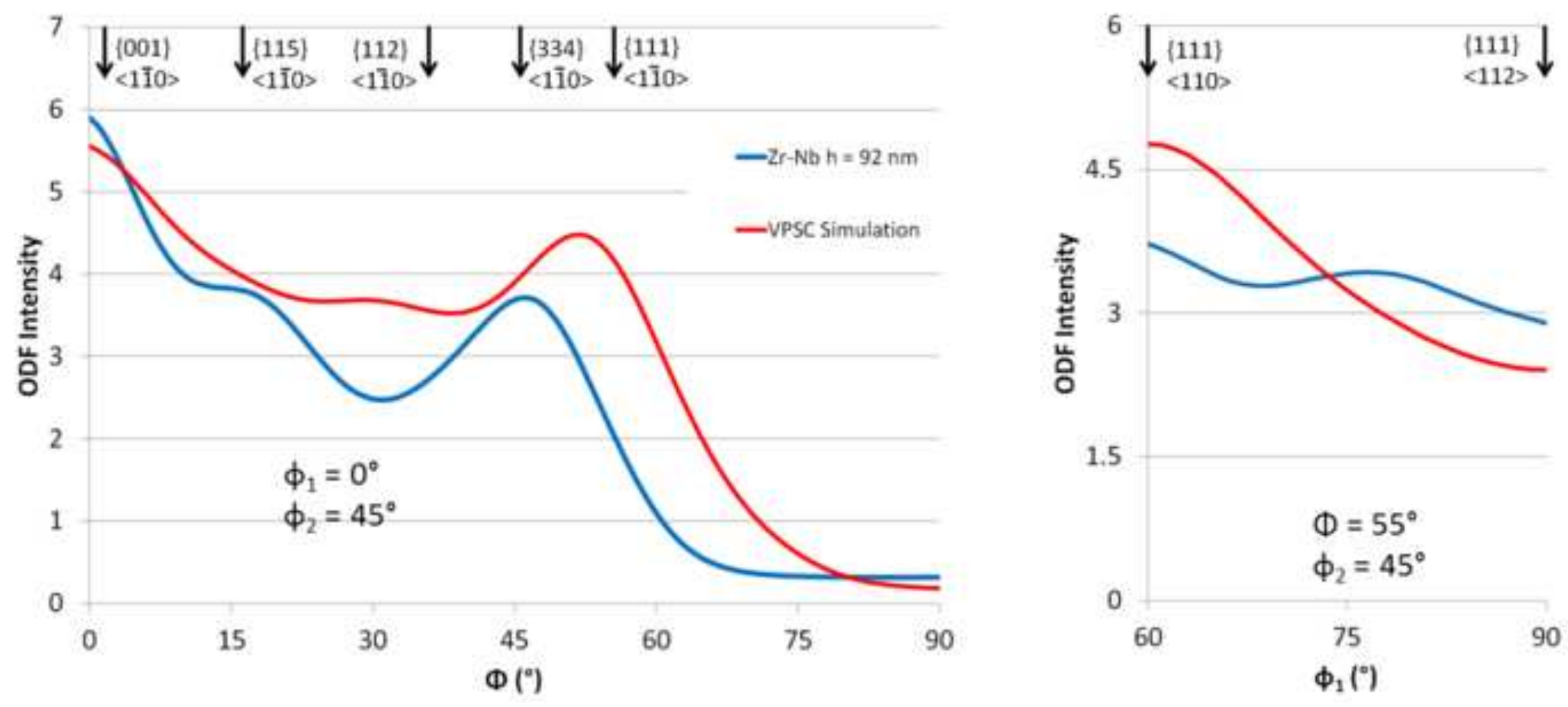

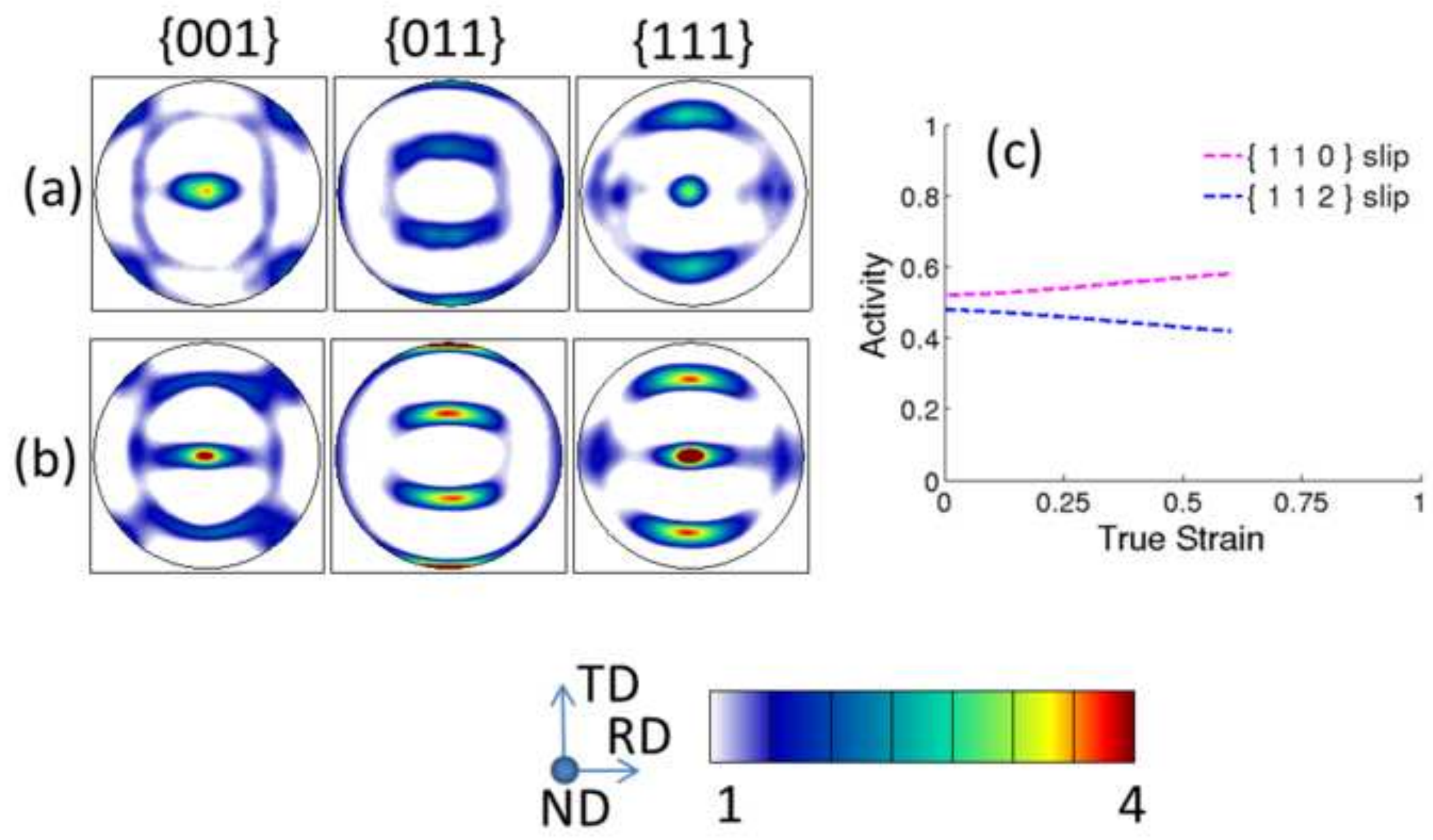
(a)

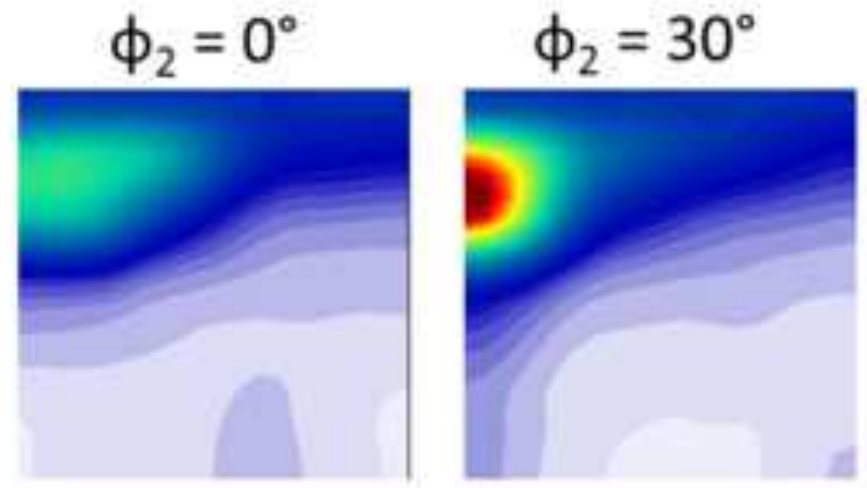

(b)
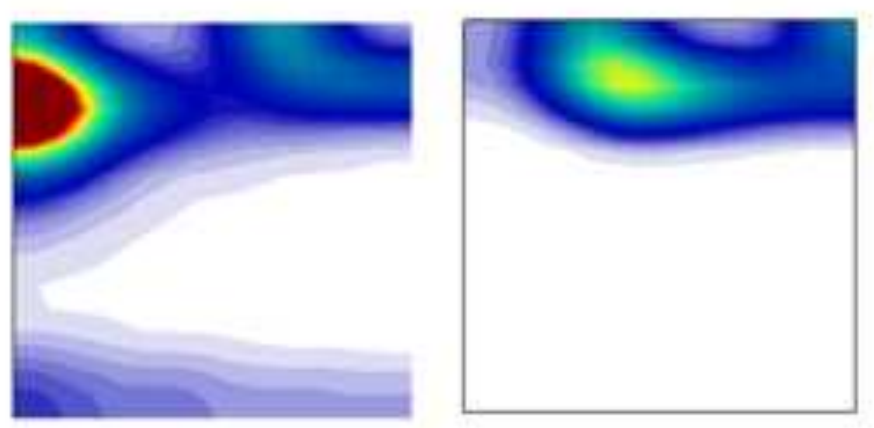

(c)

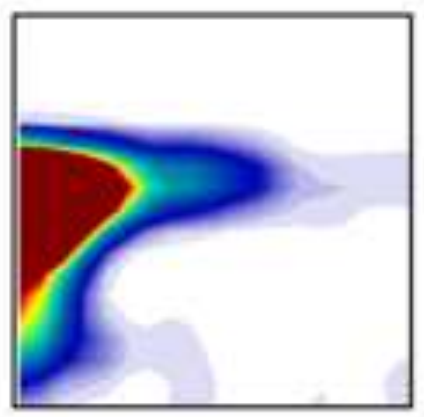

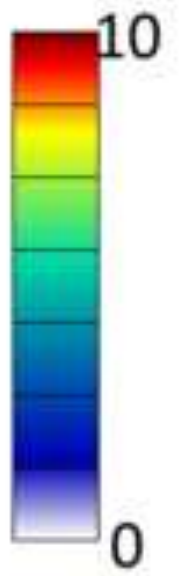

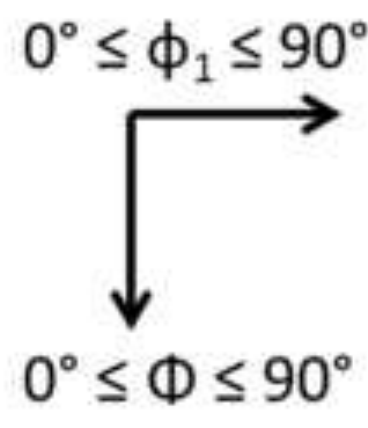

(d)

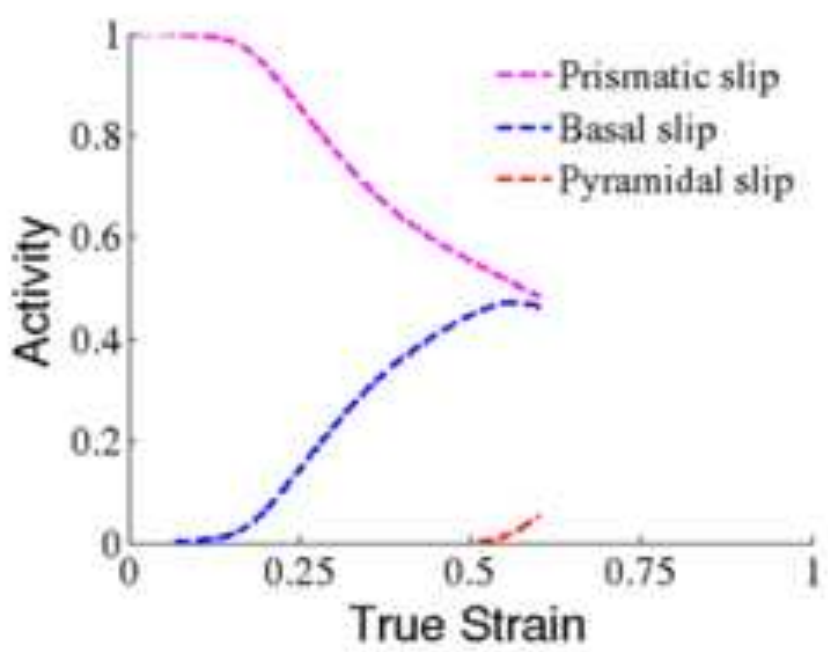

(e)

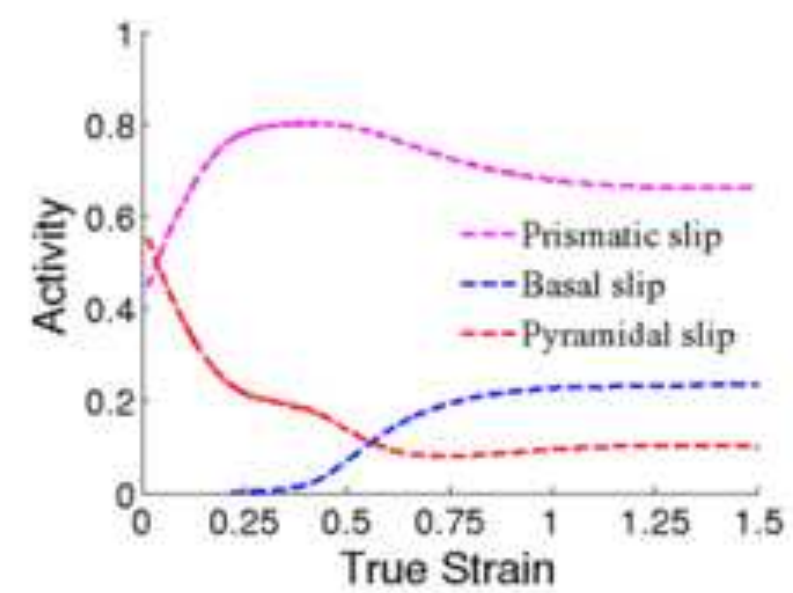




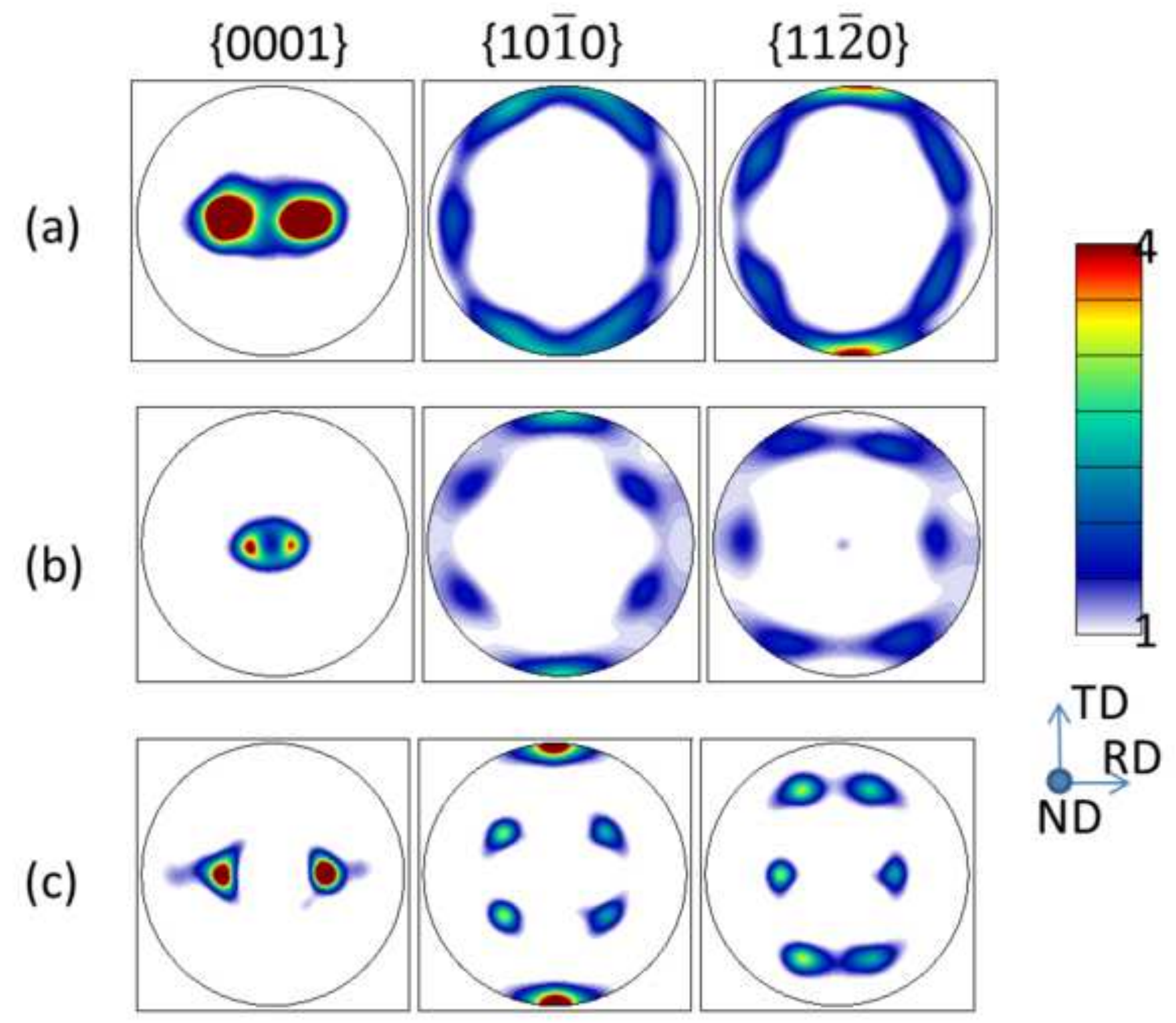

